\title{
Cannabinoid type-1 receptor blockade restores neurological phenotypes in two models for Down syndrome
}

Alba Navarro-Romero', Anna Vázquez-Oliver ${ }^{1}$, Maria Gomis-González', Carlos GarzónMontesinos $^{2}$, Rafael Falcón-Moya ${ }^{2}$, Antoni Pastor ${ }^{3,4}$, Elena Martín-García ${ }^{1,5}$, Nieves Pizarro ${ }^{3}$, Arnau Busquets-Garcia ${ }^{1} \uparrow$, Jean-Michel Revest ${ }^{6}$, Pier-Vincenzo Piazza ${ }^{6}$, Fátima Bosch ${ }^{7}$, Mara Dierssen $^{8,9,10}$, Rafael de la Torre ${ }^{3,4}$, Antonio Rodríguez-Moreno ${ }^{2}$, Rafael Maldonado ${ }^{1 \ddagger}$, Andrés Ozaita 1 **

Affiliations:

${ }^{1}$ Laboratory of Neuropharmacology-NeuroPhar. Department of Experimental and Health Sciences. University Pompeu Fabra, 08003 Barcelona, Spain.

${ }^{2}$ Laboratory of Cellular Neuroscience and Plasticity. Department of Physiology, Anatomy and Cell Biology, University Pablo de Olavide, Ctra Utrera km. 1, 41013 Seville, Spain.

${ }^{3}$ Integrative Pharmacology and Systems Neuroscience Research Group, Hospital del Mar Medical Research Institute, 08003 Barcelona, Spain.

${ }^{4}$ CIBER Pathophysiology of obesity and nutrition, Institute of Health Carlos III, 28029 Madrid, Spain.

${ }^{5}$ Department of Psychobiology and Methodology of Health Sciences, Universitat Autònoma de Barcelona, Spain

${ }^{6}$ INSERM U1215, Neurocentre Magendie, Physiopathology and therapeutic approaches of stress-related diseases, 33077 Bordeaux, France.

${ }^{7}$ Center of Animal Biotechnology and Gene Therapy (CBATEG), Spain; Department of Biochemistry and Molecular Biology, School of Veterinary Medicine, Universitat Autònoma de Barcelona, 08193 Bellaterra, Spain; CIBER Diabetes and associated metabolic disorders (CIBERDEM), 08017 Madrid, Spain.

${ }^{8}$ Cellular \& Systems Neurobiology, Systems Biology Program, Centre for Genomic Regulation (CRG), The Barcelona Institute of Science and Technology, 08003 Barcelona, Spain.

${ }^{9}$ CIBER Rare disorders (CIBERER), Spain.

${ }^{10}$ Hospital del Mar Medical Research Institute, 08003 Barcelona, Spain.

*Corresponding author: Andrés Ozaita. Laboratory of Neuropharmacology-NeuroPhar. Department of Experimental and Health Sciences. Univ. Pompeu Fabra. C/Dr Aiguader 88, 08003 Barcelona, Spain. Phone: 34-93-316-0823; Fax: 34-93-316-0901; E-mail: andres.ozaita@upf.edu; ORCID: 0000-0002-2239-7403

\#Equal contribution.

$\dagger$ Present address: INSERM U1215, NeuroCentre Magendie, Endocannabinoids and Neuroadaptation Group, 33077 Bordeaux, France.

Conflict of Interest: A.B.-G., R.M. and A.O. declare intellectual property of the patent PCT/EP2013/055728. The remaining authors declare no conflict of interest. 


\section{Abstract}

Intellectual disability is the most limiting hallmark of Down syndrome, for which there is no gold-standard clinical treatment yet. The endocannabinoid system is a widespread neuromodulatory system involved in multiple functions including learning and memory processes. Alterations of this system contribute to the pathogenesis of several neurological and neurodevelopmental disorders. However, the involvement of the endocannabinoid system in the pathogenesis of Down syndrome has not been explored before. We used the best-characterized preclinical model of Down syndrome, the segmentally trisomic Ts65Dn model. In male Ts65Dn mice, cannabinoid type-1 receptor (CB1R) expression was enhanced and its function increased in hippocampal excitatory terminals. Knockdown of CB1R in the hippocampus of male Ts65Dn mice restored hippocampal-dependent memory. Concomitant with this result, pharmacological inhibition of CB1R restored memory deficits, hippocampal synaptic plasticity and adult neurogenesis in the subgranular zone of the dentate gyrus. Notably, the blockade of CB1R also normalized hippocampal-dependent memory in female Ts65Dn mice. To further investigate the mechanisms involved, we used a second transgenic mouse model overexpressing a single gene candidate for Down syndrome cognitive phenotypes, the dual specificity tyrosinephosphorylation-regulated kinase 1A (DYRK1A). CB1R pharmacological blockade similarly improved cognitive performance, synaptic plasticity and neurogenesis in transgenic male Dyrk1A mice. Our results identify CB1R as a novel druggable target potentially relevant for the improvement of cognitive deficits associated with Down syndrome.

Keywords: Down syndrome, intellectual disability, cognitive deficits, cannabinoid receptor type1, endocannabinoid system, hippocampus. 


\section{Highlights}

- CB1R function is enhanced at hippocampal excitatory terminals of Ts65Dn mice

- Genetic and pharmacological CB1R blockade rescues memory deficits in Ts65Dn mice

- CB1R blockade rescues memory deficits in transgenic mice over-expressing Dyrk1A

- $\mathrm{CB} 1 \mathrm{R}$ is a novel target worth exploring in Down syndrome cognitive impairment 


\section{Introduction}

Down syndrome, derived from the complete or partial trisomy of human chromosome 21 (Hsa21), is the main genetic cause of intellectual disability affecting 1 in 700-1,000 live births (Dierssen, 2012; Parker et al., 2010). Nowadays, intellectual disability is the most limiting feature of Down syndrome subjects' daily life, a condition for which there is no available treatment in the clinical practice, although partially effective treatments are under investigation (Gardiner, 2014). Down syndrome subjects display low intelligence quotients, and learning and memory deficits, especially in hippocampus-related cognitive domains (Dierssen, 2012; Pennington et al., 2003).

Based on the homology of the Hsa21 to the mouse chromosomes Mmu16, Mmu17 and Mmu10, several Down syndrome trisomic mouse models have been developed (Dierssen, 2012; Herault et al., 2017). The most studied is the Ts65Dn mouse which carries an extra copy of part of the mouse chromosome 16 resulting in trisomy of around 90 conserved protein-coding gene orthologues to Hsa21 (Reeves et al., 1995). Additionally, Down syndrome has been modeled by overexpressing individual genes, such as the dual specificity tyrosine-phosphorylation-regulated kinase 1A (Dyrk1A), a gene localized in HSA21q22.2 proposed to contribute to the cognitive phenotype of the syndrome (Altafaj et al., 2001). Both, the Ts65Dn and the TgDyrk1A mouse models show a marked cognitive impairment with deficits in hippocampal-dependent memory (Altafaj et al., 2001; Fernandez et al., 2007; Reeves et al., 1995). Several mechanisms have been proposed to underlie these cognitive deficits, including alterations in hippocampal synaptic plasticity, adult neurogenesis of the hippocampal dentate gyrus and excitatory/inhibitory balance of neuronal circuits (Clark et al., 2006; Contestabile et al., 2013; Kleschevnikov et al., 2004; Pons-Espinal et al., 2013). Interestingly, the endocannabinoid system (ECS), a neuromodulatory 
system involved in synaptic homeostasis and plasticity fine-tunes all of these processes (Alger, 2002; Augustin and Lovinger, 2018; Marsicano and Lafenêtre, 2009; Monory et al., 2015; Prenderville et al., 2015) but its possible role in the cognitive deficits of Down syndrome has not yet been explored. The ECS is composed of two main cannabinoid receptors, the cannabinoid type-1 and type-2 receptors (CB1R and $\mathrm{CB} 2 \mathrm{R}$, respectively), their endogenous ligands (endocannabinoids) and the enzymes involved in endocannabinoid metabolism (Mechoulam and Parker, 2013). The ECS is involved in learning and memory processes (Marsicano and Lafenêtre, 2009; Puighermanal et al., 2012). Particularly, CB1R seems to be key regulator on memory processes since the activation or blocking of this receptor have a direct impact on cognitive function (Akirav, 2011; Busquets-Garcia et al., 2015; Zanettini et al., 2011).

In this study, we revealed the involvement of the ECS in the neurological alterations of two relevant mouse models for Down syndrome. Together we pinpointed the CB1R as a target to restore the characteristic cognitive phenotypes on both models. 


\section{Materials and Methods}

\section{Animals}

All animal procedures were conducted following ARRIVE (Animals in Research: Reporting In Vivo Experiments) guidelines (Kilkenny et al., 2010) and standard ethical guidelines (European Communities Directive 2010/63/EU). Procedures were approved by the local ethical committee (Comitè Ètic d'Experimentació Animal-Parc de Recerca Biomèdica de Barcelona, CEEAPRBB).

Ts65Dn experimental mice were obtained by repeated backcrossing Ts65Dn females to C57BL/6JEiJ x C3Sn.BLiA-Pde6b+/DnJ F1 hybrid males. The parental generation was obtained from The Jackson Laboratory. Euploid littermates of Ts65Dn mice served as wild-type (WT) controls. Transgenic mice for Dyrk1A (TgDyrk1A) and WT littermates were obtained as described previously (Altafaj et al., 2001). Ts65Dn and TgDyrk1A mice were genotyped by PCR as previously described (Altafaj et al., 2001; Duchon et al., 2011). Animals aged between 8 and 16 weeks were used for experiments. Both males and females were used for Ts65Dn experiments; only males were used for TgDyrk1A experiments.

Mice were housed in Plexiglas cages with a maximum of 4 mice per cage, and maintained in a temperature-controlled $\left(21^{\circ} \mathrm{C} \pm 1^{\circ} \mathrm{C}\right)$ and humidity-controlled $(55 \pm 10 \%)$ environment. Food and water were available ad libitum. All the experiments were performed during the light phase of a $12 \mathrm{~h} \mathrm{light/dark} \mathrm{cycle} \mathrm{(light} \mathrm{on} \mathrm{at} 8 \mathrm{am}$; light off at $8 \mathrm{pm}$ ) in an experimental room at the animal facility. Mice were habituated to the experimental room and handled for 1 week before starting the experiments. All behavioral experiments were conducted by an observer blind to the experimental conditions. 


\section{Drug treatment}

Rimonabant (Sanofi-Aventis) and NESS 0327 (Cayman Chemical, Ann Arbor) were diluted in $5 \%$ ethanol, 5\% Cremophor EL and 90\% saline. They were injected in a volume of $10 \mathrm{ml} / \mathrm{kg}$ of body weight. Drugs were administered daily by intraperitoneal (i.p.) injection during 7 days. The test phase of the cognitive tasks, electrophysiological recordings and neurogenesis analysis were performed $24 \mathrm{~h}$ after last injection of the treatment.

For the surgery procedure, ketamine hydrochloride (Imalgène; Merial Laboratorios S.A.) and medetomidine hydrochloride (Domtor; Esteve) were mixed and dissolved in sterile $0.9 \%$ physiological saline and administered i.p. in a volume of $10 \mathrm{ml} / \mathrm{kg}$ of body weight. Atipamezole hydrochloride (Revertor; Virbac) and meloxicam (Metacam; Boehringer Ingelheim, Rhein) were dissolved in sterile $0.9 \%$ physiological saline and administered subcutaneously in an injection volume of $10 \mathrm{ml} / \mathrm{kg}$ of body weight. Gentamicine (Genta-Gobens; Laboratorios Normon) was dissolved in sterile $0.9 \%$ physiological saline and administered i.p. in an injection volume of 10 $\mathrm{ml} / \mathrm{kg}$ of body weight. For perfusion, ketamine hydrochloride and xylazine hydrocloride (Sigma) were mixed and dissolved in $5 \%$ ethanol and $95 \%$ distilled water.

\section{Behavioral tests}

Novel object-recognition test (NORT). It was performed following a protocol previously described (Puighermanal et al., 2009). Briefly, on day 1 mice were habituated to a V-shaped maze for 9 min. On day 2, two identical objects (familiar objects) were located at the end of each corridor for 9 min and the time that the mice spent exploring each object was computed. Twentyfour hours later, one of the familiar objects was replaced by a new object (novel object). The time spent exploring each of the objects was computed to calculate a discrimination index. A 
discrimination index was calculated as the difference between the time spent exploring the novel object minus the time exploring the familiar object divided by the total exploration time (addition of the time exploring both objects). Object exploration was defined as the orientation of the nose towards the object at a distance of less than $2 \mathrm{~cm}$. A higher discrimination index is considered to reflect greater memory retention for the familiar object. Mice that explored less than $10 \mathrm{sec}$ both objects were excluded from the analysis. Total exploration time was considered as a measure of general activity during the test and did not show significant differences between different genotypes or treatments in the present study. Drug administration was performed immediately after habituation and training phases the $6^{\text {th }}$ and $7^{\text {th }}$ respective days of treatment. Test was performed $24 \mathrm{~h}$ after the last administration.

Novel place-recognition test (NPRT). Mice were first habituated for 10 min to an empty open field during two consecutive days. On day 3 mice were trained for 10 min with two identical objects (training phase) located at two corners of the open field. Twenty-four hours later, on the test phase, one of the objects was located in a different corner (novel location), and the time spent exploring both objects in the novel and familiar locations was computed to calculate the discrimination index similar to above. Mice that explored less than $5 \mathrm{sec}$ both objects were excluded from the analysis. Total exploration time was considered as a measure of general activity during the test and did not show significant differences between different genotypes or treatments in the present study. Drug administration was performed immediately after habituation and training phases the $5^{\text {th }}, 6^{\text {th }}$ and $7^{\text {th }}$ days of treatment. Test was performed $24 \mathrm{~h}$ after the last administration.

Locomotor activity. Locomotor activity was assessed for 30 min after 3 days of treatment $24 \mathrm{~h}$ after the last drug administration. Individual locomotor activity boxes $(9 \times 20 \times 11 \mathrm{~cm})$ 
(Imetronic) were used in a low luminosity environment (5 lux). The number of horizontal movements was detected by a line of photocells located $2 \mathrm{~cm}$ above the floor.

\section{Immunoblot}

Brain tissue was rapidly dissected, immediately frozen on dry ice and stored at $-80{ }^{\circ} \mathrm{C}$ until used. Samples were processed following a protocol previously described (Ozaita et al., 2007) to obtain cytosolic and solubilized membrane proteins. The primary antibodies used were: antiCB1R (rabbit and guinea pig, 1:500, CB1-Rb-Af380 and CB1-GP-Af530 Frontier Institute Co.Ltd), anti-FAAH (mouse, 1:1,200, ab54615, Abcam), anti-NAPE-PLD (guinea pig, 1:1000, NAPE-PLD-GP-Af720-1, Frontier Institute Co.Ltd), anti-MAGL (rabbit, 1:300, ab24701, Abcam), anti-DAGL $\alpha$ (guinea pig 1:300, Frontier Institute Co.Ltd, DGLa-GP-Af380-1), antiactin (mouse, 1:50,000, MAB1501, MerckMillipore). Primary antibodies were detected with horseradish peroxidase-conjugated anti-rabbit, anti-mouse or anti-guinea pig antibodies and visualized by enhanced chemiluminescence detection (Luminata Forte Western HRP substrate, MerckMillipore). Digital images were acquired on a ChemiDoc XRS System (Bio-Rad) and quantified by The Quantity One software v4.6.3 (Bio-Rad). Optical density values for target proteins were normalized to actin as loading control in the same sample and expressed as a percentage of control group (WT).

\section{$R N A$ extraction and reverse transcription}

Hippocampal tissues were rapidly dissected and stored at $-80^{\circ} \mathrm{C}$ until used. Isolation of total RNA was performed using the RNeasy Mini kit (QIAGEN) according to the manufacturer's instructions. Total RNA concentration was measured using a NanoDrop spectrophotometer (Thermo Fisher Scientific). Reverse transcription was performed with $100 \mathrm{ng}$ of total RNA from each animal to produce cDNA in a $20-\mu 1$ reaction using the High Capacity cDNA Reverse 
Transcription kit (Applied Biosystems) according to the manufacturer's instructions. The cDNAs from brain tissues were diluted $1: 2$ and stored at $-20^{\circ} \mathrm{C}$ until use.

\section{Quantitative real-time PCR analysis}

Real-time PCR was carried out in a $10 \mu 1$ reaction using SYBR Green PCR Master Mix (Roche) according to the manufacturer's protocol with a QuantStudio 12K Flex Real-Time PCR System (Applied Biosystems). The following primers previously described (Cutando et al., 2013; Puighermanal et al., 2017) specific for mouse were used: Cnrl (sense, 5'CCTGGGAAGTGTCATCTTTGT -3'; antisense, 5'- GGTAACCCCACCCAGTTTGA -3') and $\beta$-actin (sense, 5'-CGTGAAAAGATGACCCAGATCA-3'; antisense, 5'CACAGCCTGGATGGCTACGT-3'). Quantification was performed by using the comparative CT Method ( $\triangle \Delta \mathrm{CT}$ Method). All the samples were tested in triplicate and the relative expression values were normalized to the expression value of $\beta$-actin. The fold change was calculated using the equation $2^{(-\Delta \Delta C t)}$.

\section{Electrophysiological recordings}

Hippocampal slices were prepared following a protocol previously described (Andrade-Talavera et al., 2016). Mice were anesthetized with isoflurane (2\%) and decapitated for slice preparation. Briefly, after decapitation, the whole brain, containing the two hippocampi, was removed into ice-cold solution (I) consisting of (in mM): $126 \mathrm{NaCl}, 3 \mathrm{KCl}, 1.25 \mathrm{KH}_{2} \mathrm{PO} 4,2 \mathrm{MgSO} 4,2 \mathrm{CaCl}_{2}$, $26 \mathrm{NaHCO}_{3}$, and 10 glucose $(\mathrm{pH} 7.2,300 \mathrm{mOs} / \mathrm{ml})$, and positioned on the stage of a vibratome slicer and cut to obtain transverse hippocampal slices $(350 \mu \mathrm{m})$, which were maintained continuously oxygenated for at least $1 \mathrm{~h}$ before use. All experiments were carried out at room temperature $\left(22-25^{\circ} \mathrm{C}\right)$. For experiments, slices were continuously perfused with the solution described above. To study evoked excitatory (eEPSCs) and inhibitory (eIPSCs) postsynaptic 
currents, whole-cell patch-clamp recording of pyramidal cells located in the CA1 field of the hippocampus were obtained under visual guidance by infrared differential interference contrast (DIC) microscopy. The neurons were verified as pyramidal cells through their characteristic voltage response to a current step protocol. The neurons were recorded in voltage-clamp configuration with a patch clamp amplifier (Multiclamp 700B) and the data were acquired using pCLAMP 10.2 software (Molecular Devices). To evoke eEPSCs, electrical pulses were delivered to Schaffer collaterals axons and to evoke eIPSCs electrical pulses were delivered to interneurons situated in the stratum oriens. Patch electrodes were pulled from borosilicate glass tubes and they had a resistance of 4-7 $\mathrm{M} \Omega$ when filled with (in $\mathrm{mM}$ ): $120 \mathrm{CsCl}, 8 \mathrm{NaCl}, 1$ $\mathrm{MgCl}_{2}, 0.2 \mathrm{CaCl}_{2}, 10$ HEPES, 2 EGTA and 20 QX-314 (pH 7.2, 290 mOsm). Experiments were performed at $-70 \mathrm{mV}$. Cell recordings were excluded from the analysis if the series resistance changed by more than $15 \%$ during the recording. All recordings were low-pass filtered at $3 \mathrm{kHz}$ and acquired at $10 \mathrm{kHz}$. eEPSC were isolated by adding to the perfusion solution bicuculline (20 $\mu \mathrm{M})$ to block $\mathrm{GABA}_{\mathrm{A}}$ receptors. Inhibitory postsynaptic currents (eIPSCs) were isolated adding to the perfusion solution D-AP5 $(50 \mu \mathrm{M})$ and NBQX $(10 \mu \mathrm{M})$ to block NMDA and AMPA/Kainate receptors, respectively. Mean amplitude of eEPSCs and eIPSCs was quantified the last 4 min where the effect of WIN55,212-2 was maximum before recovery.

Field excitatory postsynaptic potentials (fEPSPs) were recorded in the CA1 region of the hippocampus and were evoked by stimulation with a stimulating electrode placed on the Schaffer collateral $(0.2 \mathrm{~Hz})$. Extracellular recording electrodes were filled with the solution I. A stimulusresponse curve (1-160 $\mu \mathrm{A}$, mean of five fEPSPs at each stimulation strength) was compiled for the different mice used. 
For plasticity experiments, fEPSPs were evoked at $0.2 \mathrm{~Hz}$ by a monopolar stimulation electrode placed in the stratum radiatum using brief current pulses (200 $\mu \mathrm{s}, 0.1-0.2 \mathrm{~mA})$. Stimulation was adjusted to obtain a fEPSP peak amplitude of approximately $1 \mathrm{mV}$ during control conditions. After a stable fEPSP baseline period of $10 \mathrm{~min}$. Long-term potentiation was induced by a theta burst stimulation (TBS) protocol consisting in 5 episodes of 10 train stimulus at $5 \mathrm{~Hz}$, each one with 4 pulses at $100 \mathrm{~Hz}$. Recordings lasted 60 and 120 min after LTP induction. For paired-pulse ratio (PPR) experiments, two fEPSPs were evoked $40 \mathrm{~ms}$ apart for $0.5 \mathrm{~min}$ at baseline frequency (6 times) at the beginning of the baseline recording and again $2 \mathrm{~h}$ after applying the plasticity protocol. The PPR was expressed as the slope of the second fEPSP divided by the slope of the first fEPSP.

Data were analyzed using the Clampfit 10.2 software (Molecular Devices). The last 5 min of recording were used to estimate changes in synaptic efficacy compared to baseline. LTP was quantified by comparing the mean fEPSP slope over the 60 and 120 min post-tetanus period with the mean fEPSP slope during the baseline period and calculating the percentage change from 5 last min.

\section{Endocannabinoid quantification by liquid chromatography-tandem mass spectrometry}

The quantification of endocannabinoids and related compounds was based on the methodology previously described in plasma (Pastor et al., 2014), adapted for the extraction of endocannabinoids from brain tissue. The following N-acylethanolamines and 2-acyl glycerols were quantified: N-arachidonoylethanolamine or anandamide (AEA), Ndocosatetraenoylethanolamine (DEA), N-docosahexaenoylethanolamine (DHEA), 2arachidonoyl glycerol (2-AG), 2-linoleoyl glycerol (2-LG) and 2-oleoyl glycerol (2-OG). Halfright hippocampus $(17.5 \pm 1.7 \mathrm{mg})$ or half whole brain $(226.3 \pm 14.05 \mathrm{mg})$ of mice were placed 
in a $1 \mathrm{ml}$ Wheaton glass homogenizer and spiked with $25 \mu \mathrm{l}$ of a mix of deuterated internal standards dissolved in acetonitrile. The mix contained $5 \mathrm{ng} / \mathrm{ml} \mathrm{AEA-d4,} 5 \mathrm{ng} / \mathrm{ml}$ DHEA-d4, 5 $\mu \mathrm{g} / \mathrm{ml} 2-\mathrm{AG}-\mathrm{d} 5$, and $10 \mu \mathrm{g} / \mathrm{ml}$ 2-OG-d5. All internal standards were purchased from Cayman Chemical (Ann Harbor), except for 2-OG-d5 (Toronto Research Chemicals). Tissues were homogenized on ice with $700 \mu \mathrm{l}$ a mixture of $50 \mathrm{mM}$ Tris- $\mathrm{HCl}$ buffer (pH 7.4): methanol (1:1) and the homogenates were transferred to $12 \mathrm{ml}$ glass tubes. The homogenizer was washed twice with $0.9 \mathrm{ml}$ of the same mixture and the contents were combined into the tube giving an approximate volume of $2.5 \mathrm{ml}$ of homogenate. The homogenization process took less than $5 \mathrm{~min}$ per sample and homogenates were kept on ice until organic extraction to minimize the ex-vivo generation of endocannabinoids. Next, homogenates were extracted with $5 \mathrm{ml}$ chloroform over $20 \mathrm{~min}$ by placing the tubes in a rocking mixer. Tubes were centrifuged at 1,700 $\mathrm{g}$ over $5 \mathrm{~min}$ at room temperature. The lower organic phase was transferred to clean glass tubes, evaporated under a stream of nitrogen in a $39^{\circ} \mathrm{C}$ water bath and extracts were reconstituted in $100 \mu$ of a mixture water:acetonitrile $(10: 90, \mathrm{v} / \mathrm{v})$ with $0.1 \%$ formic acid $(\mathrm{v} / \mathrm{v})$ and transferred to high performance liquid chromatography vials with glass microvials. Endocannabinoids were separated using an Agilent 6410 triple quadrupole Liquid-Chromatograph equipped with a 1200 series binary pump, a column oven and a cooled autosampler $\left(4{ }^{\circ} \mathrm{C}\right)$. Chromatographic separation was carried out with a Waters C18-CSH column $(3.1 \times 100 \mathrm{~mm}, 1.8 \mu \mathrm{m}$ particle size $)$ maintained at $40{ }^{\circ} \mathrm{C}$ with a mobile phase flow rate of $0.4 \mathrm{ml} / \mathrm{min}$. The composition of the mobile phase was: A: $0.1 \%(\mathrm{v} / \mathrm{v})$ formic acid in water; B: $0.1 \%(\mathrm{v} / \mathrm{v})$ formic acid in acetonitrile. Endocannabinoids and related compounds were separated by gradient chromatography. The ion source was operated in the positive electrospray mode. The selective reaction monitoring mode was used for 
the analysis. Quantification was done by isotope dilution with the response of the deuterated internal standards and data were expressed as a percentage of control group (WT).

\section{Stereotaxic surgery and AAV9 vector injection}

To knockdown CB1R expression we used an adeno-associated viral serotype 9 (AAV9) vectormediated shRNA approach previously described (Guegan et al., 2013). The AAV9 vector was selected for its good transduction efficiency into the hippocampus (Aschauer et al., 2013). The intracranially injection of AAV9 was performed as previously described with slight modifications (Busquets-Garcia et al., 2018) in the following coordinates: anteroposterior, -1.82 $\mathrm{mm}$; mediolateral, $\pm 1.00 \mathrm{~mm}$; dorsoventral, $2.00 \mathrm{~mm}$ (Paxinos and Franklin, 2004). Mice were anaesthetized with a ketamine $(75 \mathrm{mg} / \mathrm{kg}) / \mathrm{medetomidine}(1 \mathrm{mg} / \mathrm{kg})$ mixture before they underwent stereotaxic surgery and received a bilateral hippocampal injection. The injection of $0.5 \mu \mathrm{l}$ of AAV9-shSC (control, $5.03 \times 10^{13}$ vector genomes/ml) or AAV9-shCB1R (AAV9shRNACB1A: $6.48 \times 10^{13}$ vector genomes/ml plus AAV9-shCB1B: $1.1 \times 10^{13}$ vector genomes/ml) was made through a bilateral injection cannula (33-gauge internal cannula, Plastics One) connected to a polyethylene tubing (PE-20, Plastics One) attached to a $10 \mu$ l Hamilton microsyringe (Sigma). The displacement of an air bubble inside the length of the polyethylene tubing that connected the syringe to the injection needle was used to monitor the microinjections. The volume was injected at a constant rate of $0.25 \mu \mathrm{l} / \mathrm{min}$ by using a microinfusion pump (Harvard Apparatus, Holliston) during 2 min. After infusion, the injection cannula was left in place for an additional period of 10 min to allow the fluid to diffuse and to prevent reflux, then it was slowly withdrawn during 10 additional min. After surgery, anesthesia was reversed by a subcutaneous injection of atipamezole $(2.5 \mathrm{mg} / \mathrm{kg})$. In addition, mice received an i.p. injection of gentamicine $(1 \mathrm{mg} / \mathrm{kg})$ and a subcutaneous injection of the analgesic meloxicam $(2 \mathrm{mg} / \mathrm{kg})$. For 
tropism studies, we used an AAV9 vector expressing GFP cDNA ( $4.3 \times 10^{13}$ vector genomes $\left./ \mathrm{ml}\right)$ under the control of the cytomegalovirus early enhancer/chicken $\beta$-actin (CAG) constitutive promoter and the woodchuck hepatitis post-transcriptional regulatory element (WPRE). Behavioral tests were performed three weeks after the injection.

\section{Rimonabant detection}

Rimonabant was quantified in plasma and brain samples obtained from mice treated for 7 days with vehicle or rimonabant. Samples were obtained $24 \mathrm{~h}$ after the last vehicle or rimonabant administration. Plasma samples were obtained from trunk blood recovered with EDTA (1 mM). For the analysis of these samples, $5 \mu \mathrm{l}$ of the internal standard (I.S., methachlorophenylpiperazine, $1 \mu \mathrm{g} / \mathrm{ml}$ ) was mixed with $50 \mu \mathrm{l}$ of plasma and proteins were precipitated by using $100 \mu 1$ of acetonitril. After separating and evaporating the organic phase, extracts were reconstituted with a mixture of 50:50 methanol-milliQ water. Brain tissues where weighted and homogenized with a $1 \mathrm{ml}$ Wheaton glass homogenizer in two steps: first by adding $400 \mu 1$ of $\mathrm{HCOOH} 0.1 \%$, followed by a second homogenization with $800 \mu 1$ of acetronitril. The mixture was centrifuged $10 \mathrm{~min}$ at $15,700 \mathrm{~g}, 4^{\circ} \mathrm{C}$, and supernatant was stored at $-20^{\circ} \mathrm{C}$ until used. Then, $50 \mu 1$ of the supernatant were processed following the same protocol described for plasma samples.

Samples were analyzed in an Acquity UPLC System (Waters Associates) coupled to a mass spectrometer (QuattroPremier, Watters Associates). Chromatographic separation was carried out in an Acquity BEH C18 (100 mm x $2.1 \mathrm{~mm}$ i.d., $1.7 \mu \mathrm{m})$ (Waters Associates) at a flow rate of $0.4 \mathrm{ml} / \mathrm{min}$. Ammonium formate $(1 \mathrm{mM})-\mathrm{HCOOH} 0.01 \%$ (A) and $\mathrm{MeOH}$ with ammonium formate (1 mM)-HCOOH $0.01 \%$ (B) were used as mobile phases. After keeping $40 \%$ B for 0.5 min, the gradient was increased to $95 \% \mathrm{~B}$ in 3 min and maintained at $95 \% \mathrm{~B}$ for 1 min after 
going back to initial conditions. Detection of analytes was done by the selected reaction monitoring (SRM) method, being the transitions used for identification and quantification (in bold) for each compound as follows: $465 \rightarrow 84,99, \mathbf{3 6 5}$ (rimonabant); 197 $\rightarrow 44,118,154$ (I.S.).

\section{Immunofluorescence and cell quantification}

Four hours after the last administration of rimonabant, $\operatorname{BrdU}(50 \mathrm{mg} / \mathrm{kg}$, i.p.) was also injected. Twenty-four hours later, mice were deeply anesthetized by i.p. injection $(0.2 \mathrm{ml} / 10 \mathrm{~g}$ of body weight $)$ of a mixture of ketamine $(100 \mathrm{mg} / \mathrm{kg}) / x y l a z i n e ~(20 \mathrm{mg} / \mathrm{kg})$ prior to intracardiac perfusion of cold $4 \%$ paraformaldehyde. For detections we used the following primary antibodies: anti-BrdU (mouse, 1:150, B8434, Sigma-Aldrich) and anti-Ki67 (rabbit, ab15580, 1:150, Abcam). We employed the following secondary antibodies: donkey anti-mouse (1:700, Alexa Fluor-647, A31571, Invitrogen) and donkey anti-rabbit (1:600, Alexa Fluor-488, A21206,

Life Technologies). Systematic series of coronal sections (1:6) per animal were selected, covering the rostral to caudal extension of the hippocampus (from 1.3 and $2.5 \mathrm{~mm}$ posterior to Bregma). Four brain sections per animal were used for performing immunofluorescence of Ki67 and BrdU. Brains were removed and post-fixed overnight at $4{ }^{\circ} \mathrm{C}$ in the same fixative solution. The next day, brains were moved to PB $0.1 \mathrm{M}$ at $4{ }^{\circ} \mathrm{C}$. Coronal brains sections $(50 \mu \mathrm{m})$ for immunofluorescence staining were made on vibratome Leica VT1000 S (Leica Biosystems) and stored in a cryoprotectant solution containing $30 \%$ ethylene-glycol (vol $/ \mathrm{vol}), 30 \%$ glycerol (vol/vol) at $-20{ }^{\circ} \mathrm{C}$ until they were used for immunodetections. For BrdU detection, DNA denaturalization was required. For this purpose, slices were pretreated with $2 \mathrm{~N} \mathrm{HCl}$ at $37{ }^{\circ} \mathrm{C}$ for $30 \mathrm{~min}$. Then, free-floating sections were incubated with $0.1 \mathrm{M}$ borate buffer $\mathrm{pH}=8.5$ for $15 \mathrm{~min}$ to neutralize the $\mathrm{pH}$. Afterwards, slices were rinsed in $0.9 \% \mathrm{NaCl} \mathrm{PB}$ (PBS), blocked in a solution containing 3\% normal donkey serum and $0.3 \%$ Triton X-100 in $0.1 \mathrm{M}$ PBS (NDS-T- 
PBS) at room temperature for $2 \mathrm{~h}$ and incubated in the same solution with primary antibodies at $4{ }^{\circ} \mathrm{C}$. Forty-eight hours later, slices were rinsed with $0.1 \mathrm{M}$ PBS and incubated with secondary antibodies in NDS-T-PBS for $2 \mathrm{~h}$ at room temperature. Then, sections were rinsed and mounted onto gelatin-coated slides with Mowiol mounting medium. Images of stained sections were obtained with a confocal microscope TCS SP8 LEICA (Leica Biosystems) using a dry objective (20x) with a sequential line scan at $1024 \times 1024$ pixel resolution. The images were obtained choosing a representative $10 \mu \mathrm{m} \mathrm{Z}$-stack from the slice. The density of positive cells (Ki67 or BrdU) was quantified manually over the projection visualized after the application of an optimal automatic threshold (MaxEntropy) from Fiji software (ImageJ). To avoid counting twice overlapped cells, all pictures of the z-stack were individually checked. The number of positive cells was calculated as the mean of total number of cells counted referred to the volume of the SGZ $\left(\mu \mathrm{m}^{3}\right)$. Positive cells density was referred to that calculated for the control group.

\section{Experimental design and statistical analysis}

Mice were randomly assigned to experimental groups. Sample size choice was based on previous studies (Busquets-Garcia et al., 2016, 2013) and it is listed in figure legends for each experiment. Data were analyzed with Statistica Software using unpaired Student's $t$-test or twoway ANOVA for multiple group comparisons. Subsequent post hoc analysis (Newman-Keuls) was used when required (significant interaction between factors). Comparisons were considered statistically significant when $p<0.05$. Outliers ( \pm 2 s.d. from the mean) were excluded. 


\section{Results}

\section{CB1R function is enhanced at hippocampal excitatory terminals of Ts65Dn mice}

We first analyzed the expression of the main components of the ECS in the hippocampus of young-adult Ts65Dn male mice. Protein expression of the most abundant cannabinoid receptor in the brain, CB1R, was increased in comparison to wild-type (WT) mice (Fig. 1A) (Student's ttest: $p=0.0003)$. Conversely, the Cnrl mRNA levels remained unaltered in hippocampus of Ts65Dn mice (Fig. S1A). We also assessed CB1R protein expression in the rest of the brain and no changes were observed between WT and Ts65Dn mice (Fig. S1B). In addition, the expression of the main enzymes involved in the synthesis (N-acyl-phosphatidylethanolamine-hydrolyzing phospholipase D, NAPE-PLD and diacylglycerol- $\alpha$ lipase, DAGL $\alpha$ ) and degradation (fatty acid amide hydrolase, FAAH and monoacylglycerol lipase, MAGL) of the main endocannabinoids, 2AG and anandamide, was unaffected in the hippocampus of Ts65Dn mice (Fig. S1C).

To assess the functional consequences of CB1R overexpression on synaptic transmission, we performed whole-cell patch-clamp recordings in CA1 pyramidal neurons from acute slices of WT and Ts65Dn mice. We found that the CB1R agonist WIN55,212-2 (300 nM) produced an enhanced inhibitory effect on the amplitude of evoked excitatory postsynaptic currents (eEPSCs) (mean \pm s.e.m., $\mathrm{WT}=76.44 \pm 10.80$ and $\mathrm{Ts} 65 \mathrm{Dn}=43.87 \pm 7.94$, Student's t-test: $p=0.031$ ), but had no effect on evoked inhibitory postsynaptic currents (eIPSCs) in trisomic mice compared to controls (mean \pm s.e.m., WT=67.27 \pm 10.73 and Ts65Dn=63.4 \pm 8.23 ) (Fig. 1, B-C). To determine whether the enhanced inhibitory effect on the amplitude of eEPSCs produced by WIN55,212-2 had a postsynaptic or a presynaptic component, we estimated the noise-free coefficient of variation $(\mathrm{CV})$ of the synaptic responses, in control conditions and in the presence of WIN55,212-2. We calculated the ratio of both CVs and plotted the observed change in the mean 
EPSC amplitude (M) versus the change in the statistic $1 / \mathrm{CV}^{2}$, which denotes the variance of the evoked response (Malinow and Tsien, 1990; Rodríguez-Moreno et al., 1997; Rodríguez-Moreno and Paulsen, 2008). This approach uncovered that, in control and Ts65Dn mice, the reduction in eEPSC amplitude by WIN55,212-2 closely follows the predicted relation for a presynaptic (diagonal dashed line) rather than a postsynaptic action (horizontal dashed line) (Fig. 1D). Together, these data revealed an overall increased function of CB1R at excitatory terminals of CA1 hippocampal region in Ts65Dn mice.

We also determined the levels of endocannabinoids (arachidonoylethanolamine, AEA and 2arachidonoylglycerol, 2-AG), and related $\mathrm{N}$-acylethanolamine (N-docosatetraenoylethanolamine, DEA and N-docosahexaenoylethanolamine, DHEA) and 2-monoacylglycerol (2linoleoylglycerol, 2-LG and 2-oleoylglycerol, 2-OG) compounds in hippocampus and whole brain. AEA, DEA and DHEA were decreased in hippocampus (AEA: $p=0.008$; DEA: $p=0.015$; DHEA: $p=0.047)$ and DHEA was also decreased in whole brain $(p=0.008)$ (Table 1).

\section{Rescue of hippocampal-dependent memory deficits by CBIR knockdown in Ts65Dn mice}

As CB1R signaling has a major role in regulating memory processes (Akirav, 2011; BusquetsGarcia et al., 2015; Zanettini et al., 2011), we next evaluated the role of hippocampal CB1R overexpression in the cognitive impairment of Ts65Dn mice. To this aim, we used a set of adeno-associated viral serotype 9 (AAV9) vectors, as previously described (Guegan et al., 2013). AAV9-shRNAs against CB1R (shCB1R) or AAV9-scramble shRNA (control, shSC) were bilaterally injected into the hippocampus (Fig. 2A depicts AAV9 tropism and hippocampal diffusion). Three weeks after the infusion, we assessed hippocampal-dependent memory using the novel object-recognition test (NORT). Then, we obtained brain samples to analyze CB1R protein levels from hippocampal homogenates. Intra-hippocampal infusion of shCB1R, but not 
shSC, significantly reduced cognitive impairment in the NORT (two-way ANOVA interaction: $\mathrm{F}(1,23)=7.51, p=0.011$; post hoc Newman-Keuls: WT shSC vs Ts65Dn $\operatorname{shSC} p=0.009$; Ts65Dn shSC vs Ts65Dn shCB1R $p=0.011$ ) (Fig. 2B) and reduced the expression of CB1R in hippocampus of Ts65Dn mice (Student's t-test: $p=0.035$ ) to the level observed in WT mice (Fig.

2, C and D). These improvements were not related to modifications in the exploratory behavior since total object exploration times did not change significantly among experimental conditions (Fig. S2A). shCB1R infusion also reduced CB1R expression in WT mice $(p=0.048)$ without effects on NORT performance (Fig. 2, B and E). Thus, the normalization of CB1R expression in hippocampus was sufficient to rescue hippocampal memory deficits in Ts65Dn mice.

CBIR pharmacological targeting rescues hippocampal-dependent memory deficits in Ts65Dn mice

We then tested whether a pharmacological intervention was suitable to treat memory deficits in Down syndrome using systemic administration of the CB1R specific antagonist/inverse agonist rimonabant in Ts65Dn mice. We administered rimonabant $(1 \mathrm{mg} / \mathrm{kg}$, intraperitoneal injection (i.p.)) for 7 days. Twenty-four hours after the last administration, the test phase of the NORT was performed (Fig. 3A). By that time, the presence of rimonabant was detected in plasma and brain samples of treated mice (1.5-6 ng/ml and 100-200 pg/mg of wet tissue, respectively; $\mathrm{n}=6)$. Subchronic treatment of rimonabant improved object-recognition memory of male and female Ts65Dn mice (male: two-way ANOVA, interaction, $\mathrm{F}(1,31)=8.42, p=0.0068$; post hoc Newman-Keuls, WT VEH vs Ts65Dn VEH $p=0.0025$; Ts65Dn VEH vs Ts65Dn RIM $p=0.0028$; female: two-way ANOVA, interaction, $\mathrm{F}(1,38)=4.13, p=0.048$; post hoc Newman-Keuls, WT VEH vs Ts65Dn VEH $p=0.0006$; Ts65Dn VEH vs Ts65Dn RIM $p=0.0011$ ) (Fig. 3, B and C). Given this positive result, we also assessed place-recognition which is more dependent on the 
hippocampus itself with less influence of the cortico-hippocampal system (Barker and Warburton, 2011; Warburton and Brown, 2015) using the novel place-recognition test (NPRT). Notably, rimonabant administration also rescued the phenotype of Ts65Dn mice in the NPRT (two-way ANOVA, interaction, $\mathrm{F}(1,34)=4.14, p=0.049$; post hoc Newman-Keuls, WT VEH vs Ts65Dn VEH $p=0.0014$; Ts65Dn VEH vs Ts65Dn RIM $p=0.0125$ ) (Fig. 3D). No significant differences were detected in total object exploration times among the different experimental groups in neither of the two tests (Fig. S2, B-D). Furthermore, rimonabant treatment did not affect locomotor activity neither in WT nor in Ts65Dn mice (Fig. S2E).

We also assessed the effect of a CB1R neutral antagonist, NESS 0327 (Ruiu et al., 2003), over memory deficits of Ts65Dn mice. A sub-chronic treatment of NESS 0327 (0.1 mg/kg, 7 days), also improved NORT memory performance in Ts65Dn mice (two-way ANOVA, interaction: $\mathrm{F}(1,20)=5.85, p=0.025$; post hoc Newman-Keuls, WT VEH vs Ts65Dn VEH $p=0.014$; Ts65Dn VEH vs Ts65Dn NESS $0327 p=0.043$ ) (Fig. 3E) indicating that CB1R antagonists without CB1R inverse agonist profile are also able to normalize memory deficits in Ts65Dn mice. Again, alterations in total object exploration times were not observed among the different experimental groups (Fig. S2F). Interestingly, none of the memory tests revealed an effect of the treatment in WT mice (Fig. 3, B-E) demonstrating that blocking CB1R specifically improves hippocampaldependent memory in Ts65Dn mice.

CBIR pharmacological targeting improves hippocampal synaptic plasticity and cell proliferation in $T s 65$ Dn mice

Since alterations in hippocampal synaptic plasticity and adult neurogenesis play a role in Down syndrome cognitive impairment (Clark et al., 2006; Kleschevnikov et al., 2004), we assessed whether pharmacological CB1R targeting could also rescue those phenotypes. We studied long- 
term potentiation (LTP) elicited by theta-burst stimulation (TBS) which is reduced in hippocampal CA3-CA1 synapses of Ts65Dn mice (Costa and Grybko, 2005). We analyzed early-LTP and late-LTP (E-LTP and L-LTP; 60 and 120 min post-tetanus period, respectively) of hippocampal slices from WT and Ts65Dn mice treated for 7 days with vehicle or rimonabant (1 $\mathrm{mg} / \mathrm{kg}$, i.p., last administration $24 \mathrm{~h}$ before slice collection). As expected, overall LTP was decreased in Ts65Dn mice compared to WT mice treated with vehicle. Interestingly, rimonabant administration normalized the Ts65Dn deficit in L-LTP (E-LTP, two-way ANOVA, interaction: $\mathrm{F}(1,23)=4.24, p=0.0508$; L-LTP, two-way ANOVA, interaction: $\mathrm{F}(1,23)=4.815, p=0.038$; post hoc Newman-Keuls, WT VEH vs Ts65Dn VEH $p=0.021$; Ts65Dn VEH vs Ts65Dn RIM $p=0.046$ ) (Fig. 4, A and B; see Fig. S3, A and B, for control groups), again with no effect of the treatment was revealed in WT mice. Changes in LTP were not due to differences in basal synaptic transmission as similar input/output curves were observed between experimental groups (Fig. S3, C and D). To determine the site of expression of LTP, we analyzed paired-pulse facilitation ratios (PPRs) during baseline and $120 \mathrm{~min}$ after the application of the induction protocol. The analysis of PPRs before and after LTP did not show differences in any of the experimental groups (Fig. S3E) suggesting that this form of LTP is postsynaptically expressed.

In addition, we studied adult neurogenesis, since Ts65Dn mice show a reduction in cell proliferation (Belichenko and Kleschevnikov, 2011; Clark et al., 2006), that can be quantified by the number of cells expressing Ki67, an endogenous marker of cell proliferation. Consistent with previous reports, Ts65Dn male mice treated with vehicle for 7 days (i.p., last administration $24 \mathrm{~h}$ before brain perfusion) showed a decreased number of Ki67+ cells in the subgranular zone of the dentate gyrus (Fig. 4C). Treatment with rimonabant $(1 \mathrm{mg} / \mathrm{kg})$ rescued this phenotype, with Ki67+ cell counts similar to WT controls, without modifying Ki67+ cell counts in WT mice 
(two-way ANOVA, interaction: $\mathrm{F}(1,17)=7.544, p=0.013$; post hoc Newman-Keuls, WT VEH vs Ts65Dn VEH $p=0.034$; Ts65Dn VEH vs Ts65Dn RIM $p=0.049$ ) (Fig. 4C). Thus, sub-chronic administration of rimonabant normalized defective synaptic plasticity and cellular proliferation in the hippocampus of Ts65Dn mice.

\section{CBIR pharmacological targeting is effective in the transgenic model overexpressing Dyrk1A}

Dyrk1A overexpression in mice recapitulates cognitive deficits and brain alterations of Down syndrome (Altafaj et al., 2001; Pons-Espinal et al., 2013). In addition, normalization of the dosage of this gene in Ts65Dn mice rescues cognitive, LTP and cellular proliferation deficits (García-Cerro et al., 2014) indicating that Dyrk1A overexpression is involved in the phenotypes normalized after CB1R blockade. Therefore, we investigated the protein expression of the CB1R on the hippocampus of a transgenic model overexpressing only this kinase, the TgDyrk1A mice (Altafaj et al., 2001). We observed an increase of CB1R in hippocampus of TgDyrk1A in comparison to WT mice (Student's t-test: $p=0.02$ ) (Fig. S4). We also studied the expression of the main endocannabinoid metabolic enzymes and we did not observed differences between WT and TgDyrk1A mice (Fig. S4). Then, we assessed whether CB1R inhibition also improves memory deficits in TgDyrk1A mice. These mice showed a marked deficit in NORT that was rescued after rimonabant treatment $(1 \mathrm{mg} / \mathrm{kg}$, i.p., 7 days $)$. A reduced dose of rimonabant $(0.1$ $\mathrm{mg} / \mathrm{kg}$ ) was almost as effective in improving cognitive performance of this model (two-way ANOVA, interaction: $\mathrm{F}(1,41)=12.08, p=0.000008$; post hoc Newman-Keuls, WT VEH vs TgDyrk1A VEH $p=0.0001$; TgDyrk1A VEH vs TgDyrk1A RIM $0.1 \mathrm{mg} / \mathrm{kg} p=0.0002$; TgDyrk1A VEH vs TgDyrk1A RIM $1 \mathrm{mg} / \mathrm{kg} p=0.0001$ ) (Fig. 5A). In addition, TgDyrk1A mice also displayed deficits in the NPRT that were normalized after a sub-chronic treatment of rimonabant ( $1 \mathrm{mg} / \mathrm{kg}$ ) (two-way ANOVA, interaction: $\mathrm{F}(1,49)=5.66, p=0.021$; post hoc 
Newman-Keuls, WT VEH vs TgDyrk1A VEH $p=0.018$; TgDyrk1A VEH vs TgDyrk1A RIM $p=0.012)$ (Fig. 5B). Notably, NESS 0327 treatment $(0.1 \mathrm{mg} / \mathrm{kg}, 7$ days $)$ also improved memory performance in TgDyrk1A mice (two-way ANOVA, interaction: $\mathrm{F}(1,23)=4.73, p=0.04$; post hoc Newman-Keuls, WT VEH vs TgDyrk1A VEH $p=0.025$; TgDyrk1A VEH vs TgDyrk1A NESS $0327 p=0.017$ ) (Fig. 5C) further supporting CB1R as a relevant target in the cognitive improvement of this mouse line. Alterations in total object exploration times were not observed among the different experimental conditions (Fig. S5, A-C).

We also studied the effect of rimonabant after treatment withdrawal in TgDyrk1A mice. Remarkably, the beneficial effects of rimonabant treatment were observed after 2 but not 4 weeks of washout in NORT ( 2 weeks: two-way ANOVA, interaction: $\mathrm{F}(1,20)=4.53, p=0.045$; post hoc Newman-Keuls, WT VEH vs TgDyrk1A VEH $p=0.0005$; TgDyrk1A VEH vs TgDyrk1A RIM $p=0.001$ ) (Fig. S6, A-D).

We next examined whether rimonabant treatment had an impact over hippocampal synaptic plasticity and cell proliferation in this model. We found a decrease in hippocampal L-LTP in slices of TgDyrk1A in comparison to WT while after LTP induction a transient facilitation of fEPSPs slope was clearly observed in TgDyrk1A mice similar to wild-type mice (Fig. 6A). Subchronic rimonabant administration (7 days, $1 \mathrm{mg} / \mathrm{kg}$, i.p.) normalized L-LTP in TgDyrk1A mice and did not have any effect on WT mice (L-LTP, two-way ANOVA, interaction: $F(1,30)=8.761$, $p=0.0059$; post hoc Newman-Keuls, WT VEH vs TgDyrk1A VEH $p=0.0066$; TgDyrk1A VEH vs TgDyrk1A RIM $p=0.001$ ) (Fig. 6, A and B; see Fig. S7, A and B for control groups). No differences in basal synaptic transmission were observed between experimental conditions, as input/output curves were similar (Fig. S7, C and D). No differences were observed in the PPRs 
before and after LTP in any of the experimental groups indicating that this form of LTP is postsynaptically expressed (Fig. S7E).

TgDyrk1A mice also showed defects in adult neurogenesis. Conversely to what occurs in Ts65Dn mice, we observed a trend towards an increase of Ki67+ cells in TgDyrk1A mice, though this modification did not reach significance (Fig. 6C). Since this increase seems to be secondary to a cell cycle arrest (Pons-Espinal et al., 2013) rather than an increase in cell proliferation rate, we analyzed the progenitors exiting the cell cycle. To address this specific issue in TgDyrk1A, we injected a set of rimonabant $(1 \mathrm{mg} / \mathrm{kg}) /$ vehicle treated mice (7 days, i.p.) with a single dose of the DNA intercalating agent BrdU, $24 \mathrm{~h}$ before brain perfusion to in vivo label those cells actively proliferating. We later quantified cells that exited the cell cycle by counting cells that had incorporated BrdU but that did not express Ki67 (BrdU+/Ki67- cells). Interestingly, while rimonabant administration slightly reduced the number of Ki67+ cells, it significantly increased BrdU+/Ki67- cells (two-way ANOVA, interaction: $F(1,15)=21.14$, $p=0.0003$; post hoc Newman-Keuls, WT VEH vs TgDyrk1A VEH $p=0.205$; TgDyrk1A VEH vs TgDyrk1A RIM $p=0.0009$ ) (Fig. 6D). This indicates that rimonabant rescued the decrease in cell cycle exit in TgDyrk1A mice. Therefore, repeated CB1R inhibition normalized hippocampal LLTP and progenitor cell proliferation derived from Dyrk1A overexpression. 


\section{Discussion}

In this study, we identified CB1R as a relevant target to improve hippocampal-dependent memory, long-term synaptic plasticity and adult neurogenesis in two relevant models for Down syndrome, the segmentally trisomic Ts65Dn model and the transgenic TgDyrk1 A model.

We first analyzed the main protein components of the ECS in the hippocampus of Ts65Dn mice since this brain area is especially impaired in Down syndrome subjects (Lott and Dierssen, 2010; Pennington et al., 2003). We revealed an increased protein expression of CB1R restricted to the hippocampus. Such increase was functionally relevant at excitatory terminals and not at inhibitory ones. Hippocampal CB1R is not distributed equally in the different cell types, presenting low expression levels on glutamatergic terminals and astrocytes, and high levels exclusively on cholecystokinin-expressing GABAergic terminals (Han et al., 2012; Kano et al., 2009; Kawamura et al., 2006). However, it has been described that the levels of expression do not correlate with their functional relevance. Glutamatergic CB1R, but not CB1R in other cells, reduced excitotoxicity in a model of epilepsy (Marsicano et al., 2003; Monory et al., 2006), and showed more effective coupling to G-protein signaling than GABAergic CB1R (Steindel et al., 2013). These data reflect the relevance of glutamatergic CB1R for hippocampal circuit activity, which function is affected in Ts65Dn mice. In this regard, an imbalance of excitatory/inhibitory neuronal circuit activity has been proposed to contribute to the cognitive deficits of the Ts65Dn mice (Best et al., 2012; Kurt et al., 2004; Potier et al., 2014; Souchet et al., 2015). It is plausible that the increased inhibition of glutamatergic neurotransmission elicited by excess glutamatergic CB1R function in Ts65Dn hippocampus would contribute to this imbalance. 
Regarding the levels of the most studied hippocampal endocannabinoids, we found a decrease of AEA and no changes on 2-AG in Ts65Dn mice. Since we did not find changes in the main enzymes responsible for the synthesis and degradation of AEA, such decrease may be secondary to alterations in the activity of these enzymes, or it may involve alterations in alternative metabolism pathways (Ueda et al., 2013). Changes in neuronal activity happening in the Ts65Dn hippocampus may also have an effect over AEA levels (Kim and Alger, 2010) contributing to the observed differences. Additionally, we cannot discard that decreased levels of AEA in hippocampus of Ts65Dn mice could lead to a decrease in biological responses dependent on this endocannabinoid such as hippocampal synaptic plasticity mediated by transient receptor potential channel 1 (TRPV1) (Chávez et al., 2010). However, it is unlikely that the decrease in AEA levels can compensate the over-expression of CB1R in the Ts65Dn hippocampus. In fact, it is 2-AG the endocannabinoid that mediates major forms of hippocampal synaptic plasticity through the activation of CB1R including depolarization-induced suppression of inhibition (DSI), depolarization-induced suppression of excitation (DSE) and inhibitory long-term depression (iLTD) (Chevaleyre and Castillo, 2003; Hashimotodani et al., 2013; Straiker and Mackie, 2005).

Alterations of AEA in Ts65Dn mice would be anatomically restricted since AEA levels detected in whole brain homogenates were not different from those in wild-type mice. Notably, our results of endocannabinoid content in whole brain extracts from young-adult Ts65Dn mice are complementary to those previously described in middle-aged 9-to-11-month-old Ts65Dn mice reporting enhanced levels of 2-AG (Lysenko et al., 2014). Middle-aged Ts65Dn mice present an Alzheimer's disease-like neuropathology including age-dependent cognitive decline, cholinergic neurodegeneration in the basal forebrain, increased levels of amyloid precursor protein (APP), 
amyloid- $\beta$ peptide and tau hyperphosphorylation (Hamlett et al., 2016) although amyloid plaques are absent. In this regard, an increase in 2-AG but not AEA has been described after stereotaxic injection of beta-amyloid peptide in naïve rats (van der Stelt et al., 2006). Therefore, specific increase in 2-AG levels observed in middle-age Ts65Dn mice could be related to the associated Alzheimer's disease-like neuropathology. Alternatively, the relative increase in older Ts65Dn mice may be secondary to age-dependent changes, since alterations in the expression and activity of endocannabinoid metabolic enzymes and particularly, in MAGL and DAGL $\alpha$, have been described in aged rodents (Pascual et al., 2013; Piyanova et al., 2015).

We next assessed a genetic approach to specifically target CB1R in hippocampus of Ts65Dn mice. The attenuation of CB1R expression by shRNA rescued hippocampal-dependent memory in Ts65Dn mice suggesting that the over-expression of CB1R is contributing to cognitive deficits of Ts65Dn mice. This result was reproduced by pharmacological approaches using the CB1R specific antagonist/inverse agonist rimonabant and the neutral antagonist NESS 0327 further supporting the relevance of this new target to tackle cognitive impairments in Down syndrome. The administration of rimonabant in Ts65Dn mice did not alter CB1R expression in hippocampus (data not shown). This is consistent with previous findings in rats where a longer treatment of rimonabant at a dose of $10 \mathrm{mg} / \mathrm{kg}$ did not modify the hippocampal density of CB1R (Martín-García et al., 2010). This observation indicates that the effect of the treatment would not depend upon changes in the expression of the receptor.

The improvement on cognitive function of Down syndrome mouse models with the CB1R inhibition was accompanied by changes in synaptic plasticity and adult neurogenesis. CB1R subchronic blockade restored impaired LTP in CA3-CA1 synapses. Notably, conditional deletion of $\mathrm{CB} 1 \mathrm{R}$ in glutamatergic or GABAergic neurons was shown to increase or decrease hippocampal 
LTP, respectively (Monory et al., 2015), indicating that CB1R changes in either population is sufficiently to alter long-term plasticity. These results further support the participation of glutamatergic CB1R enhanced function in the hippocampal LTP alterations of Ts65Dn mice, and the beneficial effect of CB1R sub-chronic blockade over this phenotype.

Several compounds that normalize adult neurogenesis in Ts65Dn mice (Bianchi et al., 2010; Contestabile et al., 2013) also normalize LTP and associated memory functions. We evaluated adult neurogenesis and we showed a decrease in cell proliferation in young Ts65Dn mice, which is consistent with previous results (Belichenko and Kleschevnikov, 2011; Clark et al., 2006). Notably, rimonabant treatment normalized alterations in adult neurogenesis in Ts65Dn without modifying that in WT mice. Although several studies have addressed the role of CB1R in adult neurogenesis, there is no general consensus since the effects depend on the precise experimental conditions (Prenderville et al., 2015). In this regard, it is plausible that the main effect of subchronic CB1R blockade in Ts65Dn mice is indirectly associated to the regulation of adult neurogenesis through the modification of local network activity in the dentate gyrus of the hippocampus driving to cell proliferation (Lehmann et al., 2005).

Our study used a well characterized mouse model of the HSA21 trisomy, but the perfect Down syndrome mouse model does not exist. It is important to mention that the Ts65Dn mouse model is trisomic for 90 ortholog genes to those found in HSA21 but also for other 35 coding genes not in trisomy in Down syndrome individuals. Therefore, although the construct validity of the Ts65Dn model is not perfect, it recapitulates most of the phenotypes observed in Down syndrome patients at different ages (Aziz et al., 2018). Other models with better construct validity, such as the Dp16 or the TTS, show phenotypes milder than those found in the Ts65Dn model and they do not present some of the phenotypes observed in Down syndrome patients, 
probably due to the lack of a freely segregating chromosome (Aziz et al., 2018; Belichenko et al., 2015). In order to investigate whether our findings were not limited to the Ts65Dn model, we turned to a model in which Dyrk1A is overexpressed, the TgDyrk1A model (Altafaj et al., 2001). This mouse model was constructed using the inducible sheep metallothionein-Ia promoter and, although spatial and temporal regulation of the transgene may not match with the endogenous Dyrk1A gene, it was demonstrated that the expression in cortex of DYRK1A in this model is similar to Down syndrome cerebral fetal tissue (Toiber et al., 2010). Moreover, this model reproduces several Down syndrome phenotypes (Altafaj et al., 2001; Martínez de Lagrán et al., 2004; Pons-Espinal et al., 2013).

DYRK1A gene is directly associated to the characteristic neurological phenotype in Down syndrome subjects. Normalization of DyrklA gene dosage in Ts65Dn mice have revealed a key role of this protein in memory performance, hippocampal synaptic plasticity, adult neurogenesis and neuronal circuit excitatory/inhibitory imbalance (Ahn et al., 2006; García-Cerro et al., 2014; Souchet et al., 2014). Interestingly, we observed an increase of CB1R in hippocampus of TgDyrk1A mice indicating a link between DYRK1A and CB1R expression. In addition, as previously described, TgDyrk1A mice showed a significant impairment in the NORT (de la Torre et al., 2014) and also in the NPRT. We also found a decrease of hippocampal LTP in this mouse model in agreement with those Down syndrome models sharing the trisomic expression of Dyrk1A (Belichenko et al., 2009, 2015; Costa and Grybko, 2005; Siarey et al., 2005). In addition, normalizing DyrklA dosage on Ts65Dn mice increases LTP to control values (GarcíaCerro et al., 2014), which fit with our results on LTP obtained in the TgDyrk1A model. CB1R blockade rescued the performance of TgDyrk1A mice in both NORT and NPRT and deficits in LTP. Interestingly, in agreement with previous reports (Pons-Espinal et al., 2013), we observed a 
non-significant increase on Ki67+ cells and a decrease on BrdU+/Ki67- cells in TgDyrk1A mice which may be explained by a reduction on cell cycle exit. According to a previous study, this reduction is secondary to an elongation of G2 phase during progenitor cell cycle (Pons-Espinal et al., 2013), which in fact, has also been described in Ts65Dn mice (Contestabile et al., 2007). Therefore, both Ts65Dn and TgDyrk1A models may present decreased cell proliferation and cell cycle exit, but probably at different extents, which explains the different phenotype observed with the proliferative marker Ki67. Notably, CB1R sub-chronic blockade in the TgDyrk1A model significantly facilitated cell cycle exit of neuronal precursors. Together, these findings strongly indicate that CB1R signaling is implicated in the deficits derived from the increase on Dyrk1A gene dosage.

Different compounds have been tested in preclinical studies of Down syndrome. In fact, another approach targeting the ECS (JZL184 administration), improved cognitive performance and synaptic plasticity of 9-to-11-months old Ts65Dn mice (Lysenko et al., 2014). Beneficial effects of JZL184 inhibiting 2-AG metabolism in middle-aged Ts65Dn mice may be specific for the age-associated neurodegeneration and neuroinflammation. In this sense, previous studies in mouse models of Alzheimer's disease showed that JZL184 produces anti-inflammatory effects which may be obtained through a CB1R-independent mechanism (Chen et al., 2012; Piro et al., 2012). Although several compounds have improved memory deficits in Down syndrome mouse models, most of them have produced marginally positive results in clinical trials (Hart et al., 2017). We took several considerations to maximize the translational potential of our study. First, we used two mouse models whose predictive validity has been recently demonstrated for novel experimental approaches to improve intellectual performance in Down syndrome individuals (de la Torre et al., 2016, 2014). Second, we assed three different methods directed to the same target, 
CB1R, one genetic approach and two pharmacological approaches (rimonabant and NESS 0327). Third, although most experiments were carried out in male mice, we also assessed hippocampaldependent memory after CB1R blockade in female mice, showing comparable gender results. Altogether, our study highlights the effects of targeting CB1R, both genetically and pharmacologically, in two young-adult mouse models of relevance for Down syndrome, with an improvement in cognitive performance, synaptic plasticity and adult neurogenesis. These preclinical evidences pinpoint CB1R as a novel target worth exploring in the context of Down syndrome cognitive deficits. 


\section{Figure legends}

Fig. 1. CB1R function is enhanced at hippocampal CA1 excitatory terminals of Ts65Dn mice. (A) Representative immunoblots and quantification of CB1R in hippocampus from WT and Ts65Dn mice (WT, n=6; Ts65Dn, n=6). Actin immunodetection was used as housekeeping control. (B) Average time course of eEPSCs amplitude in WT and Ts65Dn slices during baseline and after bath application of WIN 55,212-2 (300 nM). Inset, traces show eEPSCs during baseline $\left(1,1^{\prime}\right)$ and after $\left(2,2^{\prime}\right)$ bath application of WIN 55,212-2 (WT, n=6; Ts65Dn, n=7). (C) Average time course of eIPSCs amplitude in WT and Ts65Dn slices during baseline (1, 1') and after $\left(2,2^{\prime}\right)$ bath application of WIN 55,212-2 (300 nM) (WT, n=5; Ts65Dn, n=5). (D) Normalized plot of $\mathrm{CV}^{-2}$ versus mean EPSCs yielded points closer to the diagonal after WIN 55,212-2 treatment. Distribution of individual data with mean \pm s.e.m. $* * * p<0.001$ (genotype effect) by Student's t-test.

Fig. 2. Injection of AAV9-shRNA against CB1R knocks down its expressions and normalizes memory deficits of Ts65Dn mice. (A) Representative images from two coronal planes of a mouse showing localization and diffusion of AAV9 expressing GFP cDNA injected in the same stereotaxic coordinates than AAV9-shSC/CB1R. (B) Discrimination index in novel object-recognition test (NORT) from WT and Ts65Dn mice injected with shSC or shCB1R in hippocampus (WT shSC, n=9; WT shCB1R, n=7; Ts65Dn shSC, n=5; Ts65Dn shCB1R, n=5). (C) Representative immunoblots and quantification of CB1R in hippocampus from Ts65Dn mice injected with shSC or shCB1R (Ts65Dn shSC, $n=5$; Ts65Dn shSCB1R, $n=5$ ). (D) Representative immunoblots and quantification of CB1R in hippocampal samples comparing control mice (WT injected with shSC) versus Ts65Dn mice injected with shCB1R (WT shSC, n=6; Ts65Dn shCB1R, $n=5$ ). (E) Representative immunoblots and quantification of CB1R in hippocampal samples from WT mice injected with shSC or shCB1R (WT shSC, n=7; WT shCB1R, n=6). Actin was used as housekeeping control. Distribution of individual data with mean \pm s.e.m. * $\mathrm{p}<0.05, * * \mathrm{p}<0.01$ (genotype effect); \# $\mathrm{p}<0.05$ (treatment effect) by Newman-Keuls post hoc test following two-way ANOVA (B) and by Student's t-test.

Fig. 3. Pharmacological targeting of CB1R improves hippocampal-dependent memory in Ts65Dn mice. (A) Schematic representation of the experimental protocol. (B-C) Discrimination index in novel object-recognition test (NORT) after a sub-chronic treatment with vehicle (VEH) or rimonabant (RIM) (1 mg/kg) of male (B) and female (C) mice (males: WT VEH, n=9; WT RIM, n=10; Ts65Dn VEH, n=7; Ts65Dn RIM, n=9; females: WT VEH, n=11; WT RIM, n=10; Ts65Dn VEH, n=11; Ts65Dn RIM, n=10). (D) Discrimination index in novel place-recognition test (NPRT) after a sub-chronic treatment with vehicle or rimonabant $(1 \mathrm{mg} / \mathrm{kg}$ ) (WT VEH, $\mathrm{n}=10$; WT RIM, n=11; Ts65Dn VEH, n=9; Ts65Dn RIM, n=8). (E) Discrimination index in NORT after a sub-chronic treatment with vehicle or NESS $0327(0.1 \mathrm{mg} / \mathrm{kg})$ (WT VEH, n=6; WT NESS 0327, n=6; Ts65Dn VEH, n=6; Ts65Dn NESS 0327, n=6). Distribution of individual 
data with mean \pm s.e.m. $* \mathrm{p}<0.05, * * \mathrm{p}<0.01$, *** $\mathrm{p}<0.001$ (genotype effect); \# $\mathrm{p}<0.05$, \#\# $\mathrm{p}$ $<0.01$ (treatment effect) by Newman-Keuls post hoc test following two-way ANOVA.

Fig. 4. Pharmacological targeting of CB1R improves hippocampal synaptic plasticity and cellular proliferation in dentate gyrus of Ts65Dn mice. (A) Average time courses of the change in the slope of fEPSP in hippocampal slices from mice treated for 7 days with vehicle (VEH) or rimonabant (RIM) (1 mg/kg). Traces represent samples of fEPSPs recorded for each experimental group before and after TBS. (B) Average LTP of the last 5 min of recordings in ELTP and L-LTP (60 and 120 min post-tetanus period respectively) (WT VEH, n=6; WT RIM, $\mathrm{n}=7$; Ts65Dn VEH, $\mathrm{n}=6$; Ts65Dn RIM, n=8). (C) Representative grey scale confocal images and average density of Ki67+ cells in the subgranular zone of the dentate gyrus of mice treated for 7 days with VEH or RIM (1 mg/kg) (WT VEH, n=5; WT RIM, n=5; Ts65Dn VEH, n=5; Ts65Dn RIM, n=6) (scale bar $=100 \mu \mathrm{m})$. Distribution of individual data with mean \pm s.e.m. $* \mathrm{p}<0.05$ (genotype effect); \# p $<0.05$ (treatment effect) by Newman-Keuls post hoc test following twoway ANOVA.

Fig. 5. CB1R targeting improves hippocampal-dependent memory in TgDyrk1A mice. (A) Discrimination index of WT and TgDyrk1A mice in novel object-recognition test (NORT) after 7 days of treatment with vehicle (VEH) or rimonabant (RIM) $0.1 \mathrm{mg} / \mathrm{kg}$ or $1 \mathrm{mg} / \mathrm{kg}$ (WT VEH, n=10; WT RIM $0.1 \mathrm{mg} / \mathrm{kg}, \mathrm{n}=7$; WT RIM $1 \mathrm{mg} / \mathrm{kg}, \mathrm{n}=6$; TgDyrk1A VEH, n=10; TgDyrk1A RIM $0.1 \mathrm{mg} / \mathrm{kg}, \mathrm{n}=6$; TgDyrk1A RIM $1 \mathrm{mg} / \mathrm{kg}, \mathrm{n}=8$ ). (B) Discrimination index in novel placerecognition test (NPRT) after 7 days of treatment with VEH or RIM (WT VEH, n=15; WT RIM, $\mathrm{n}=12$; TgDyrk1A VEH, n=12; TgDyrk1A RIM, n=14). (C) Discrimination index of mice after 7 days of treatment with VEH or NESS $0327(0.1 \mathrm{mg} / \mathrm{kg}$ ) in NORT (WT VEH, n=5; WT NESS 0327, $n=6$; TgDyrk1A VEH, $n=8$; TgDyrk1A NESS 0327, $n=7$ ). Distribution of individual data with mean \pm s.e.m. $* \mathrm{p}<0.05, * * * \mathrm{p}<0.001$ (genotype effect); \# $\mathrm{p}<0.05$, \#\#\# $\mathrm{p}<0.001$ (treatment effect) by Newman-Keuls post hoc test following two-way ANOVA.

Fig. 6. Pharmacological targeting of CB1R improves hippocampal synaptic plasticity and the number of progenitor cells exiting the cell cycle in TgDyrk1A mice. (A) Average time courses of the change in the slope of the fEPSP in hippocampal slices from mice treated for 7 days with vehicle (VEH) or rimonabant (RIM) $(1 \mathrm{mg} / \mathrm{kg})$. Traces represent samples of fEPSPs recorded for each experimental group before and after TBS. (B) Average LTP of the last 5 min of recordings in E-LTP and L-LTP (60 and 120 min post-tetanus period respectively) (WT VEH, n=8; WT RIM, n=9; TgDyrk1A VEH, n=9; TgDyrk1A RIM, n=8). (C) Representative grey scale confocal images and average density of $\mathrm{Ki} 67+$ cells in the subgranular zone of the dentate gyrus of mice treated for 7 days with VEH or RIM ( $1 \mathrm{mg} / \mathrm{kg}$ ) (WT VEH, n=4; WT RIM, n=4; TgDyrk1A VEH, n=6; TgDyrk1A RIM, n=6) (scale bar=100 $\mu \mathrm{m}$ ). (D) Representative confocal images and average density of BrdU+/Ki67- cells in the subgranular zone of the dentate gyrus of mice treated for 7 days with VEH or RIM ( $1 \mathrm{mg} / \mathrm{kg}$ ) (WT VEH, n=4; WT RIM, n=4; TgDyrk1A 
VEH, n=5; TgDyrk1A RIM, n=6) (scale bar=20 $\mu \mathrm{m}$ ). Distribution of individual data with mean \pm s.e.m. ${ }^{* *} \mathrm{p}<0.01$ (genotype effect); \#\# $\mathrm{p}<0.01$, \#\#\# $\mathrm{p}<0.001$ (treatment effect) by NewmanKeuls post hoc test following two-way ANOVA. 


\section{References}

Ahn, K.-J., Jeong, H.K., Choi, H.-S., Ryoo, S.-R., Kim, Y.J., Goo, J.-S., Choi, S.-Y., Han, J.-S., Ha, I., Song, W.-J., 2006. DYRK1A BAC transgenic mice show altered synaptic plasticity with learning and memory defects. Neurobiol. Dis. 22, 463-472.

https://doi.org/10.1016/j.nbd.2005.12.006

Akirav, I., 2011. The Role of Cannabinoids in Modulating Emotional and Non-Emotional Memory Processes in the Hippocampus. Front. Behav. Neurosci. 5, 34. https://doi.org/10.3389/fnbeh.2011.00034

Alger, B.E., 2002. Retrograde signaling in the regulation of synaptic transmission: focus on endocannabinoids. Prog. Neurobiol. 68, 247-286.

Altafaj, X., Dierssen, M., Baamonde, C., Martí, E., Visa, J., Guimerà, J., Oset, M., González, J.R., Flórez, J., Fillat, C., Estivill, X., 2001. Neurodevelopmental delay, motor abnormalities and cognitive deficits in transgenic mice overexpressing Dyrk1A (minibrain), a murine model of Down's syndrome. Hum. Mol. Genet. 10, 1915-1923. https://doi.org/10.1093/hmg/10.18.1915

Andrade-Talavera, Y., Duque-Feria, P., Paulsen, O., Rodríguez-Moreno, A., 2016. Presynaptic Spike Timing-Dependent Long-Term Depression in the Mouse Hippocampus. Cereb. Cortex 26, 3637-3654. https://doi.org/10.1093/cercor/bhw172

Aschauer, D.F., Kreuz, S., Rumpel, S., 2013. Analysis of Transduction Efficiency, Tropism and Axonal Transport of AAV Serotypes 1, 2, 5, 6, 8 and 9 in the Mouse Brain. PLoS One 8, e76310. https://doi.org/10.1371/journal.pone.0076310

Augustin, S.M., Lovinger, D.M., 2018. Functional Relevance of Endocannabinoid-Dependent 
Synaptic Plasticity in the Central Nervous System. ACS Chem. Neurosci.

acschemneuro.7b00508. https://doi.org/10.1021/acschemneuro.7b00508

Aziz, N.M., Guedj, F., Pennings, J.L.A., Olmos-Serrano, J.L., Siegel, A., Haydar, T.F., Bianchi, D.W., 2018. Lifespan analysis of brain development, gene expression and behavioral phenotypes in the Ts1Cje, Ts65Dn and Dp(16)1/Yey mouse models of Down syndrome. Dis. Model. Mech. dmm.031013. https://doi.org/10.1242/dmm.031013

Barker, G.R.I., Warburton, E.C., 2011. When is the hippocampus involved in recognition memory? J. Neurosci. 31, 10721-10731. https://doi.org/10.1523/JNEUROSCI.641310.2011

Belichenko, N.P., Belichenko, P.V., Kleschevnikov, A.M., Salehi, A., Reeves, R.H., Mobley, W.C., 2009. The Down Syndrome Critical Region Is Sufficient in the Mouse Model to Confer Behavioral, Neurophysiological, and Synaptic Phenotypes Characteristic of Down Syndrome. J. Neurosci. 29, 5938-5948. https://doi.org/10.1523/JNEUROSCI.1547-09.2009

Belichenko, P.V., Kleschevnikov, A.M., 2011. Deficiency of Adult Neurogenesis in the Ts65Dn Mouse Model of Down Syndrome, in: Genetics and Etiology of Down Syndrome. InTech, pp. 177-192. https://doi.org/10.5772/24585

Belichenko, P.V., Kleschevnikov, A.M., Becker, A., Wagner, G.E., Lysenko, L. V., Yu, Y.E., Mobley, W.C., 2015. Down Syndrome Cognitive Phenotypes Modeled in Mice Trisomic for All HSA 21 Homologues. PLoS One 10, e0134861.

https://doi.org/10.1371/journal.pone.0134861

Best, T.K., Cramer, N.P., Chakrabarti, L., Haydar, T.F., Galdzicki, Z., 2012. Dysfunctional hippocampal inhibition in the Ts65Dn mouse model of Down syndrome. Exp. Neurol. 233, 
749-757. https://doi.org/10.1016/J.EXPNEUROL.2011.11.033

Bianchi, P., Ciani, E., Guidi, S., Trazzi, S., Felice, D., Grossi, G., Fernandez, M., Giuliani, A., Calza, L., Bartesaghi, R., 2010. Early Pharmacotherapy Restores Neurogenesis and Cognitive Performance in the Ts65Dn Mouse Model for Down Syndrome. J. Neurosci. 30, 8769-8779. https://doi.org/10.1523/JNEUROSCI.0534-10.2010

Busquets-Garcia, A., Desprez, T., Metna-Laurent, M., Bellocchio, L., Marsicano, G., SoriaGomez, E., 2015. Dissecting the cannabinergic control of behavior: The where matters. BioEssays 37, 1215-1225. https://doi.org/10.1002/bies.201500046

Busquets-Garcia, A., Gomis-González, M., Guegan, T., Agustín-Pavón, C., Pastor, A., Mato, S., Pérez-Samartín, A., Matute, C., de la Torre, R., Dierssen, M., Maldonado, R., Ozaita, A., 2013. Targeting the endocannabinoid system in the treatment of fragile $X$ syndrome. Nat. Med. 19, 603-607. https://doi.org/10.1038/nm.3127

Busquets-Garcia, A., Gomis-González, M., Salgado-Mendialdúa, V., Galera-López, L.,

Puighermanal, E., Martín-García, E., Maldonado, R., Ozaita, A., 2018. Hippocampal Protein Kinase C Signaling Mediates the Short-Term Memory Impairment Induced by Delta9-Tetrahydrocannabinol. Neuropsychopharmacology 43, 1021-1031. https://doi.org/10.1038/npp.2017.175

Busquets-Garcia, A., Gomis-González, M., Srivastava, R.K., Cutando, L., Ortega-Alvaro, A., Ruehle, S., Remmers, F., Bindila, L., Bellocchio, L., Marsicano, G., Lutz, B., Maldonado, R., Ozaita, A., 2016. Peripheral and central CB1 cannabinoid receptors control stressinduced impairment of memory consolidation. Proc. Natl. Acad. Sci. 113, 9904-9909. https://doi.org/10.1073/pnas.1525066113 
Chávez, A.E., Chiu, C.Q., Castillo, P.E., 2010. TRPV1 activation by endogenous anandamide triggers postsynaptic long-term depression in dentate gyrus. Nat. Neurosci. 13, 1511-1518. https://doi.org/10.1038/nn.2684

Chen, R., Zhang, J., Wu, Y., Wang, D., Feng, G., Tang, Y.-P., Teng, Z., Chen, C., 2012. Monoacylglycerol Lipase Is a Therapeutic Target for Alzheimer's Disease. Cell Rep. 2, 1329-1339. https://doi.org/10.1016/J.CELREP.2012.09.030

Chevaleyre, V., Castillo, P.E., 2003. Heterosynaptic LTD of Hippocampal GABAergic Synapses: A Novel Role of Endocannabinoids in Regulating Excitability. Neuron 38, 461472. https://doi.org/10.1016/S0896-6273(03)00235-6

Clark, S., Schwalbe, J., Stasko, M.R., Yarowsky, P.J., Costa, A.C.S.S., 2006. Fluoxetine rescues deficient neurogenesis in hippocampus of the Ts65Dn mouse model for Down syndrome. Exp. Neurol. 200, 256-261. https://doi.org/10.1016/j.expneurol.2006.02.005

Contestabile, A., Fila, T., Ceccarelli, C., Bonasoni, P., Bonapace, L., Santini, D., Bartesaghi, R., Ciani, E., 2007. Cell cycle alteration and decreased cell proliferation in the hippocampal dentate gyrus and in the neocortical germinal matrix of fetuses with Down syndrome and in Ts65Dn mice. Hippocampus 17, 665-678. https://doi.org/10.1002/hipo.20308

Contestabile, A., Greco, B., Ghezzi, D., Tucci, V., Benfenati, F., Gasparini, L., 2013. Lithium rescues synaptic plasticity and memory in Down syndrome mice. J. Clin. Invest. 123, 348361. https://doi.org/10.1172/JCI64650

Costa, A.C.S., Grybko, M.J., 2005. Deficits in hippocampal CA1 LTP induced by TBS but not HFS in the Ts65Dn mouse: A model of Down syndrome. Neurosci. Lett. 382, 317-322. https://doi.org/10.1016/j.neulet.2005.03.031 
Cutando, L., Busquets-Garcia, A., Puighermanal, E., Gomis-González, M., Delgado-García, J.M., Gruart, A., Maldonado, R., Ozaita, A., 2013. Microglial activation underlies cerebellar deficits produced by repeated cannabis exposure. J. Clin. Invest. 123, 2816-31. https://doi.org/10.1172/JCI67569

de la Torre, R., de Sola, S., Hernandez, G., Farré, M., Pujol, J., Rodriguez, J., Espadaler, J.M., Langohr, K., Cuenca-Royo, A., Principe, A., Xicota, L., Janel, N., Catuara-Solarz, S., Sanchez-Benavides, G., Bléhaut, H., Dueñas-Espín, I., Del Hoyo, L., Benejam, B., BlancoHinojo, L., Videla, S., Fitó, M., Delabar, J.M., Dierssen, M., TESDAD study group, 2016. Safety and efficacy of cognitive training plus epigallocatechin-3-gallate in young adults with Down's syndrome (TESDAD): a double-blind, randomised, placebo-controlled, phase 2 trial. Lancet. Neurol. 15, 801-810. https://doi.org/10.1016/S1474-4422(16)30034-5

de la Torre, R., De Sola, S., Pons, M., Duchon, A., de Lagran, M.M., Farré, M., Fitó, M., Benejam, B., Langohr, K., Rodriguez, J., Pujadas, M., Bizot, J.C., Cuenca, A., Janel, N., Catuara, S., Covas, M.I., Blehaut, H., Herault, Y., Delabar, J.M., Dierssen, M., 2014. Epigallocatechin-3-gallate, a DYRK1A inhibitor, rescues cognitive deficits in Down syndrome mouse models and in humans. Mol. Nutr. Food Res. 58, 278-288. https://doi.org/10.1002/mnfr.201300325

Dierssen, M., 2012. Down syndrome: the brain in trisomic mode. Nat. Rev. Neurosci. 13, 844858. https://doi.org/10.1038/nrn3314

Duchon, A., Raveau, M., Chevalier, C., Nalesso, V., Sharp, A.J., Herault, Y., 2011. Identification of the translocation breakpoints in the Ts65Dn and Ts1Cje mouse lines: relevance for modeling Down syndrome. Mamm. Genome 22, 674-684. https://doi.org/10.1007/s00335-011-9356-0 
Fernandez, F., Morishita, W., Zuniga, E., Nguyen, J., Blank, M., Malenka, R.C., Garner, C.C., 2007. Pharmacotherapy for cognitive impairment in a mouse model of Down syndrome. Nat. Neurosci. 10, 411-413. https://doi.org/10.1038/nn1860

García-Cerro, S., Martínez, P., Vidal, V., Corrales, A., Flórez, J., Vidal, R., Rueda, N., Arbonés, M.L., Martínez-Cué, C., 2014. Overexpression of Dyrk1A Is Implicated in Several Cognitive, Electrophysiological and Neuromorphological Alterations Found in a Mouse Model of Down Syndrome. PLoS One 9, e106572. https://doi.org/10.1371/journal.pone.0106572

Gardiner, K., 2014. Pharmacological approaches to improving cognitive function in Down syndrome: current status and considerations. Drug Des. Devel. Ther. 9, 103. https://doi.org/10.2147/DDDT.S51476

Guegan, T., Cutando, L., Ayuso, E., Santini, E., Fisone, G., Bosch, F., Martinez, A., Valjent, E., Maldonado, R., Martin, M., 2013. Operant behavior to obtain palatable food modifies neuronal plasticity in the brain reward circuit. Eur. Neuropsychopharmacol. 23, 146-159. https://doi.org/10.1016/j.euroneuro.2012.04.004

Hamlett, E.D., Boger, H.A., Ledreux, A., Kelley, C.M., Mufson, E.J., Falangola, M.F., Guilfoyle, D.N., Nixon, R.A., Patterson, D., Duval, N., Granholm, A.-C.E., 2016. Cognitive Impairment, Neuroimaging, and Alzheimer Neuropathology in Mouse Models of Down Syndrome. Curr. Alzheimer Res. 13, 35-52.

Han, J., Kesner, P., Metna-Laurent, M., Duan, T., Xu, L., Georges, F., Koehl, M., Abrous, D.N., Mendizabal-Zubiaga, J., Grandes, P., Liu, Q., Bai, G., Wang, W., Xiong, L., Ren, W., Marsicano, G., Zhang, X., 2012. Acute Cannabinoids Impair Working Memory through 
Astroglial CB1 Receptor Modulation of Hippocampal LTD. Cell 148, 1039-1050.

https://doi.org/10.1016/J.CELL.2012.01.037

Hart, S.J., Visootsak, J., Tamburri, P., Phuong, P., Baumer, N., Hernandez, M.-C., Skotko, B.G., Ochoa-Lubinoff, C., Liogier D’Ardhuy, X., Kishnani, P.S., Spiridigliozzi, G.A., 2017. Pharmacological interventions to improve cognition and adaptive functioning in Down syndrome: Strides to date. Am. J. Med. Genet. Part A 173, 3029-3041. https://doi.org/10.1002/ajmg.a.38465

Hashimotodani, Y., Ohno-Shosaku, T., Tanimura, A., Kita, Y., Sano, Y., Shimizu, T., Di Marzo, V., Kano, M., 2013. Acute inhibition of diacylglycerol lipase blocks endocannabinoidmediated retrograde signalling: evidence for on-demand biosynthesis of 2arachidonoylglycerol. J. Physiol. 591, 4765-4776. https://doi.org/10.1113/jphysiol.2013.254474

Herault, Y., Delabar, J.M., Fisher, E.M.C., Tybulewicz, V.L.J., Yu, E., Brault, V., 2017. Rodent models in Down syndrome research: impact and future opportunities. Dis. Model. Mech. 10, 1165-1186. https://doi.org/10.1242/dmm.029728

Kano, M., Ohno-Shosaku, T., Hashimotodani, Y., Uchigashima, M., Watanabe, M., 2009. Endocannabinoid-mediated control of synaptic transmission. Physiol. Rev. 89, 309-380. https://doi.org/10.1152/physrev.00019.2008

Kawamura, Y., Fukaya, M., Maejima, T., Yoshida, T., Miura, E., Watanabe, M., Ohno-Shosaku, T., Kano, M., 2006. The CB1 Cannabinoid Receptor Is the Major Cannabinoid Receptor at Excitatory Presynaptic Sites in the Hippocampus and Cerebellum. J. Neurosci. 26, 29913001. https://doi.org/10.1523/JNEUROSCI.4872-05.2006 
Kilkenny, C., Browne, W., Cuthill, I., Emerson, M., Altman, D., 2010. Improving bioscience research reporting: The ARRIVE guidelines for reporting animal research. J. Pharmacol. Pharmacother. 1, 94. https://doi.org/10.4103/0976-500X.72351

Kim, J., Alger, B.E., 2010. Reduction in endocannabinoid tone is a homeostatic mechanism for specific inhibitory synapses. Nat. Neurosci. 13, 592-600. https://doi.org/10.1038/nn.2517

Kleschevnikov, A.M., Belichenko, P.V., Villar, A.J., Epstein, C.J., Malenka, R.C., Mobley, W.C., 2004. Hippocampal long-term potentiation suppressed by increased inhibition in the Ts65Dn mouse, a genetic model of Down syndrome. J. Neurosci. 24, 8153-8160. https://doi.org/10.1523/JNEUROSCI.1766-04.2004

Kurt, M.A., Kafa, M.I., Dierssen, M., Davies, D.C., 2004. Deficits of neuronal density in CA1 and synaptic density in the dentate gyrus, CA3 and CA1, in a mouse model of Down syndrome. Brain Res. 1022, 101-109. https://doi.org/10.1016/j.brainres.2004.06.075

Lehmann, K., Butz, M., Teuchert-Noodt, G., 2005. Offer and demand: proliferation and survival of neurons in the dentate gyrus. Eur. J. Neurosci. 21, 3205-3216. https://doi.org/10.1111/j.1460-9568.2005.04156.x

Lott, I.T., Dierssen, M., 2010. Cognitive deficits and associated neurological complications in individuals with Down's syndrome. Lancet Neurol. 9, 623-633. https://doi.org/10.1016/S1474-4422(10)70112-5

Lysenko, L. V., Kim, J., Henry, C., Tyrtyshnaia, A., Kohnz, R.A., Madamba, F., Simon, G.M., Kleschevnikova, N.E., Nomura, D.K., Ezekowitz, R.A.B.A.B., Kleschevnikov, A.M., 2014. Monoacylglycerol Lipase Inhibitor JZL184 Improves Behavior and Neural Properties in Ts65Dn Mice, a Model of Down Syndrome. PLoS One 9, e114521. 
https://doi.org/10.1371/journal.pone.0114521

Malinow, R., Tsien, R.W., 1990. Presynaptic enhancement shown by whole-cell recordings of long-term potentiation in hippocampal slices. Nature 346, 177-180. https://doi.org/10.1038/346177a0

Marsicano, G., Goodenough, S., Monory, K., Hermann, H., Eder, M., Cannich, A., Azad, S.C., Cascio, M.G., Gutiérrez, S.O., van der Stelt, M., López-Rodriguez, M.L., Casanova, E., Schütz, G., Zieglgänsberger, W., Di Marzo, V., Behl, C., Lutz, B., 2003. CB1 cannabinoid receptors and on-demand defense against excitotoxicity. Science 302, 84-88. https://doi.org/10.1126/science.1088208

Marsicano, G., Lafenêtre, P., 2009. Roles of the Endocannabinoid System in Learning and Memory, in: Current Topics in Behavioral Neurosciences. pp. 201-230. https://doi.org/10.1007/978-3-540-88955-7_8

Martín-García, E., Burokas, A., Martín, M., Berrendero, F., Rubí, B., Kiesselbach, C., Heyne, A., Gispert, J.D., Millán, O., Maldonado, R., 2010. Central and peripheral consequences of the chronic blockade of $\mathrm{CB}{ }_{1}$ cannabinoid receptor with rimonabant or taranabant. J. Neurochem. 112, 1338-13351. https://doi.org/10.1111/j.1471-4159.2009.06549.x

Martínez de Lagrán, M., Altafaj, X., Gallego, X., Martí, E., Estivill, X., Sahún, I., Fillat, C., Dierssen, M., 2004. Motor phenotypic alterations in TgDyrk1a transgenic mice implicate DYRK1A in Down syndrome motor dysfunction. Neurobiol. Dis. 15, 132-142. https://doi.org/10.1016/j.nbd.2003.10.002

Mechoulam, R., Parker, L.A., 2013. The Endocannabinoid System and the Brain. Annu. Rev. Psychol. 64, 21-47. https://doi.org/10.1146/annurev-psych-113011-143739 
Monory, K., Massa, F., Egertová, M., Eder, M., Blaudzun, H., Westenbroek, R., Kelsch, W., Jacob, W., Marsch, R., Ekker, M., Long, J., Rubenstein, J.L., Goebbels, S., Nave, K.-A., During, M., Klugmann, M., Wölfel, B., Dodt, H.-U., Zieglgänsberger, W., Wotjak, C.T., Mackie, K., Elphick, M.R., Marsicano, G., Lutz, B., 2006. The Endocannabinoid System Controls Key Epileptogenic Circuits in the Hippocampus. Neuron 51, 455-466. https://doi.org/10.1016/J.NEURON.2006.07.006

Monory, K., Polack, M., Remus, A., Lutz, B., Korte, M., 2015. Cannabinoid CB1 receptor calibrates excitatory synaptic balance in the mouse hippocampus. J. Neurosci. 35, 38423850. https://doi.org/10.1523/JNEUROSCI.3167-14.2015

Ozaita, A., Puighermanal, E., Maldonado, R., 2007. Regulation of PI3K/Akt/GSK-3 pathway by cannabinoids in the brain. J. Neurochem. 102, 1105-1114. https://doi.org/10.1111/j.14714159.2007.04642.x

Parker, S.E., Mai, C.T., Canfield, M.A., Rickard, R., Wang, Y., Meyer, R.E., Anderson, P., Mason, C.A., Collins, J.S., Kirby, R.S., Correa, A., National Birth Defects Prevention Network, 2010. Updated national birth prevalence estimates for selected birth defects in the United States, 2004-2006. Birth Defects Res. Part A Clin. Mol. Teratol. 88, 1008-1016. https://doi.org/10.1002/bdra.20735

Pascual, A.C., Gaveglio, V.L., Giusto, N.M., Pasquaré, S.J., 2013. Aging modifies the enzymatic activities involved in 2-arachidonoylglycerol metabolism. BioFactors 39, 209-220. https://doi.org/10.1002/biof.1055

Pastor, A., Farré, M., Fitó, M., Fernandez-Aranda, F., de la Torre, R., 2014. Analysis of ECs and related compounds in plasma: artifactual isomerization and ex vivo enzymatic generation of 
2-MGs. J. Lipid Res. 55, 966-977. https://doi.org/10.1194/jlr.D043794

Paxinos, G., Franklin, K.B.J., 2004. The mouse brain in stereotaxic coordinates. Elsevier Academic Press.

Pennington, B.F., Moon, J., Edgin, J., Stedron, J., Nadel, L., 2003. The neuropsychology of Down syndrome: evidence for hippocampal dysfunction. Child Dev. 74, 75-93.

Piro, J.R., Benjamin, D.I., Duerr, J.M., Pi, Y., Gonzales, C., Wood, K.M., Schwartz, J.W., Nomura, D.K., Samad, T.A., 2012. A Dysregulated Endocannabinoid-Eicosanoid Network Supports Pathogenesis in a Mouse Model of Alzheimer's Disease. Cell Rep. 1, 617-623. https://doi.org/10.1016/J.CELREP.2012.05.001

Piyanova, A., Lomazzo, E., Bindila, L., Lerner, R., Albayram, O., Ruhl, T., Lutz, B., Zimmer, A., Bilkei-Gorzo, A., 2015. Age-related changes in the endocannabinoid system in the mouse hippocampus. Mech. Ageing Dev. 150, 55-64. https://doi.org/10.1016/J.MAD.2015.08.005

Pons-Espinal, M., Martinez de Lagran, M., Dierssen, M., 2013. Environmental enrichment rescues DYRK1A activity and hippocampal adult neurogenesis in TgDyrk1A. Neurobiol. Dis. 60, 18-31. https://doi.org/10.1016/j.nbd.2013.08.008

Potier, M.-C., Braudeau, J., Dauphinot, L., Delatour, B., 2014. Reducing GABAergic inhibition restores cognitive functions in a mouse model of Down syndrome. CNS Neurol. Disord. Drug Targets 13, 8-15.

Prenderville, J.A., Kelly, Á.M., Downer, E.J., 2015. The role of cannabinoids in adult neurogenesis. Br. J. Pharmacol. 172, 3950-3963. https://doi.org/10.1111/bph.13186

Puighermanal, E., Biever, A., Pascoli, V., Melser, S., Pratlong, M., Cutando, L., Rialle, S., 
Severac, D., Boubaker-Vitre, J., Meyuhas, O., Marsicano, G., Lüscher, C., Valjent, E., 2017. Ribosomal Protein S6 Phosphorylation Is Involved in Novelty-Induced Locomotion, Synaptic Plasticity and mRNA Translation. Front. Mol. Neurosci. 10, 419. https://doi.org/10.3389/fnmol.2017.00419

Puighermanal, E., Busquets-Garcia, A., Maldonado, R., Ozaita, A., 2012. Cellular and intracellular mechanisms involved in the cognitive impairment of cannabinoids. Philos. Trans. R. Soc. B Biol. Sci. 367, 3254-3263. https://doi.org/10.1098/rstb.2011.0384

Puighermanal, E., Marsicano, G., Busquets-Garcia, A., Lutz, B., Maldonado, R., Ozaita, A., 2009. Cannabinoid modulation of hippocampal long-term memory is mediated by mTOR signaling. Nat Neurosci. 12, 1152-1158. https://doi.org/10.1038/nn.2369

Reeves, R.H., Irving, N.G., Moran, T.H., Wohn, A., Kitt, C., Sisodia, S.S., Schmidt, C., Bronson, R.T., Davisson, M.T., 1995. A mouse model for Down syndrome exhibits learning and behaviour deficits. Nat. Genet. 11, 177-184. https://doi.org/10.1038/ng1095-177

Rodríguez-Moreno, A., Herreras, O., Lerma, J., 1997. Kainate receptors presynaptically downregulate GABAergic inhibition in the rat hippocampus. Neuron 19, 893-901.

Rodríguez-Moreno, A., Paulsen, O., 2008. Spike timing-dependent long-term depression requires presynaptic NMDA receptors. Nat. Neurosci. 11, 744-745. https://doi.org/10.1038/nn.2125

Ruiu, S., Pinna, G.A., Marchese, G., Mussinu, J.-M., Saba, P., Tambaro, S., Casti, P., Vargiu, R., Pani, L., 2003. Synthesis and characterization of NESS 0327: a novel putative antagonist of the CB1 cannabinoid receptor. J. Pharmacol. Exp. Ther. 306, 363-370. https://doi.org/10.1124/jpet.103.049924 
Siarey, R.J., Villar, A.J., Epstein, C.J., Galdzicki, Z., 2005. Abnormal synaptic plasticity in the Ts1Cje segmental trisomy 16 mouse model of Down syndrome. Neuropharmacology 49, 122-128. https://doi.org/10.1016/j.neuropharm.2005.02.012

Souchet, B., Guedj, F., Penke-Verdier, Z., Daubigney, F., Duchon, A., Herault, Y., Bizot, J.-C., Janel, N., Créau, N., Delatour, B., Delabar, J.M., 2015. Pharmacological correction of excitation/inhibition imbalance in Down syndrome mouse models. Front. Behav. Neurosci. 9, 267. https://doi.org/10.3389/fnbeh.2015.00267

Souchet, B., Guedj, F., Sahún, I., Duchon, A., Daubigney, F., Badel, A., Yanagawa, Y., Barallobre, M.J., Dierssen, M., Yu, E., Herault, Y., Arbones, M., Janel, N., Créau, N., Delabar, J.M., 2014. Excitation/inhibition balance and learning are modified by Dyrk1a gene dosage. Neurobiol. Dis. 69, 65-75. https://doi.org/10.1016/j.nbd.2014.04.016

Steindel, F., Lerner, R., Häring, M., Ruehle, S., Marsicano, G., Lutz, B., Monory, K., 2013. Neuron-type specific cannabinoid-mediated G protein signalling in mouse hippocampus. J. Neurochem. 124, 795-807. https://doi.org/10.1111/jnc.12137

Straiker, A., Mackie, K., 2005. Depolarization-induced suppression of excitation in murine autaptic hippocampal neurones. J. Physiol. 569, 501-517. https://doi.org/10.1113/jphysiol.2005.091918

Toiber, D., Azkona, G., Ben-Ari, S., Torán, N., Soreq, H., Dierssen, M., 2010. Engineering DYRK1A overdosage yields Down syndrome-characteristic cortical splicing aberrations. Neurobiol. Dis. 40, 348-359. https://doi.org/10.1016/j.nbd.2010.06.011

Ueda, N., Tsuboi, K., Uyama, T., 2013. Metabolism of endocannabinoids and related Nacylethanolamines: canonical and alternative pathways. FEBS J. 280, 1874-94. 
https://doi.org/10.1111/febs.12152

van der Stelt, M., Mazzola, C., Esposito, G., Matias, I., Petrosino, S., Filippis, D. De, Micale, V., Steardo, L., Drago, F., Iuvone, T., Marzo, V. Di, 2006. Endocannabinoids and $\beta$-amyloidinduced neurotoxicity in vivo: effect of pharmacological elevation of endocannabinoid levels. Cell. Mol. Life Sci. C. 63, 1410-1424. https://doi.org/10.1007/s00018-006-6037-3

Warburton, E.C., Brown, M.W., 2015. Neural circuitry for rat recognition memory. Behav. Brain Res. 285, 131-139. https://doi.org/10.1016/J.BBR.2014.09.050

Zanettini, C., Panlilio, L. V., Aliczki, M., Goldberg, S.R., Haller, J., Yasar, S., 2011. Effects of endocannabinoid system modulation on cognitive and emotional behavior. Front. Behav. Neurosci. 5, 57. https://doi.org/10.3389/fnbeh.2011.00057 
Acknowledgements: We thank D. Real and F. Porrón for expert technical assistance, S. de la Luna (CRG) for helpful comments and G. Raz for critical reading of the manuscript. TgDyrk1A line was kindly provided by C. Fillat (IDIBAPS).

Funding: A.N.-R. is the recipient of a predoctoral fellowship (Ministerio de Educación y Cultura). A.V.-O. is the recipient of a predoctoral fellowship from Jérôme Lejeune Foundation (Spanish Delegation). M.G.-G. was partially supported by FRAXA Research Foundation. A.BG. was the recipient of a predoctoral fellowship (Ministerio de Educación y Cultura). This study was supported by Jérôme Lejeune Foundation (French Delegation) to A.O.; Instituto de Salud Carlos III (\#RD16/0017/0020) to R.M.; Ministerio de Economía, Innovación y Competitividad (MINECO) (\#BFU2015-68568-P to A.O., \#SAF2014-59648-P and \#SAF2017-84060-R to R.M.; SAF2016-79956-R to M.D.); Catalan Foundation 'La Marató de TV3' (\#2016/20-30) to E.M.G.; Junta de Andalucía (CVI-7290 to A.R.-M.); Generalitat de Catalunya (2014SGR-1547 and 2017SGR-669 to R.M.; 2014SGR-1125 to M.D.) and ICREA (Institució Catalana de Recerca i Estudis Avançats) Academia to A.O. and R.M. Grant "Unidad de Excelencia María de Maeztu", funded by the MINECO (\#MDM-2014-0370); PLAN E (Plan Español para el Estímulo de la Economía y el Empleo); FEDER funding is also acknowledged. 
A

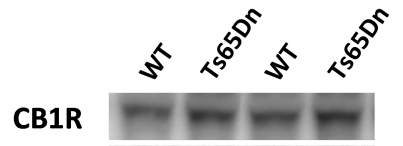

Actin

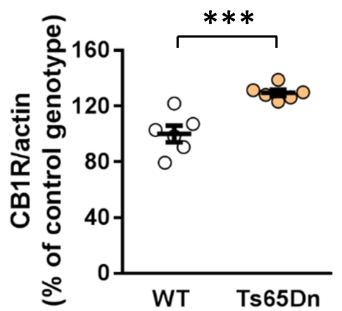

C $\circ$ WT $\circ$ Ts65Dn
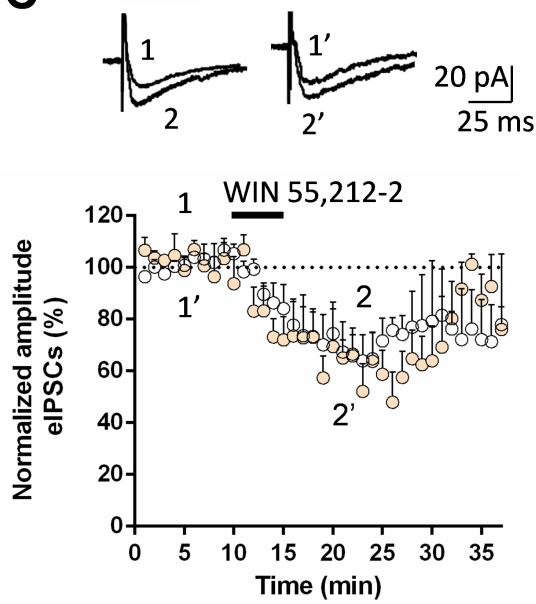

B
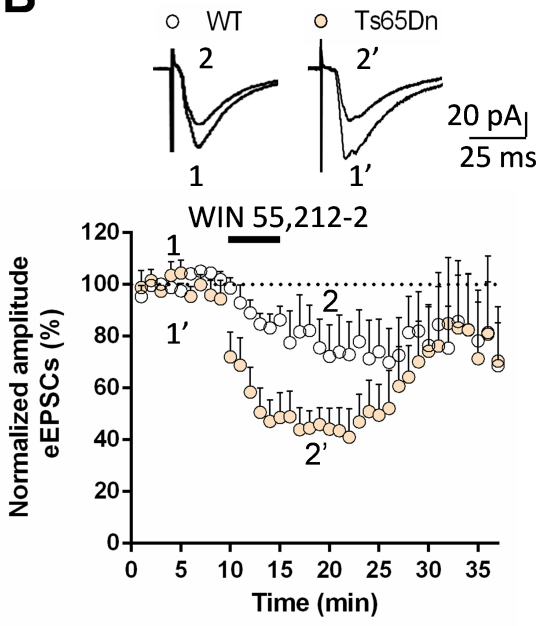

D

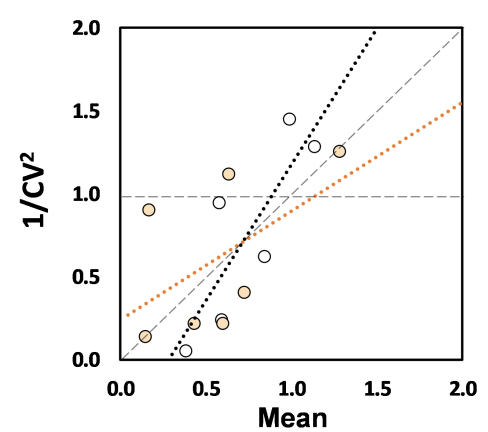


A
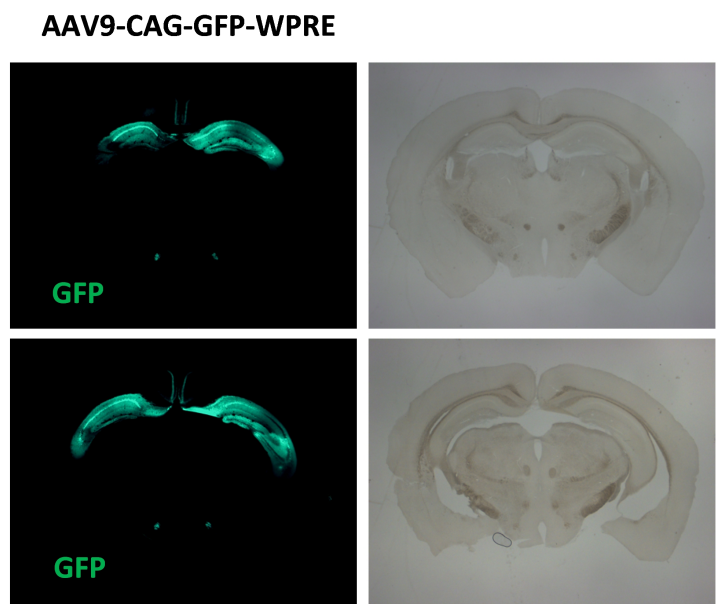

D

C

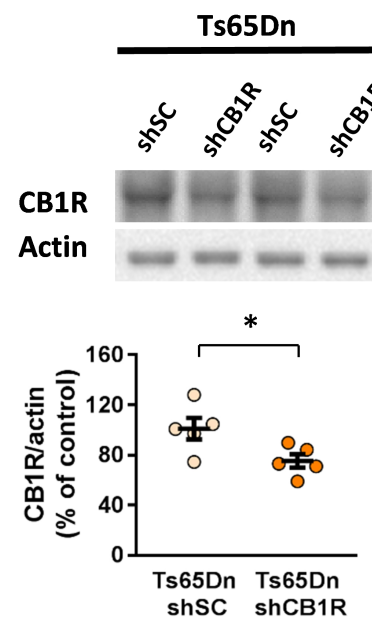

Actin
B

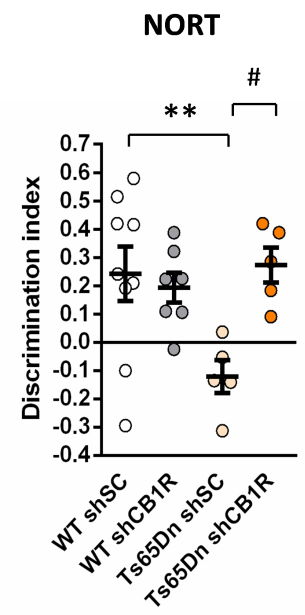

E
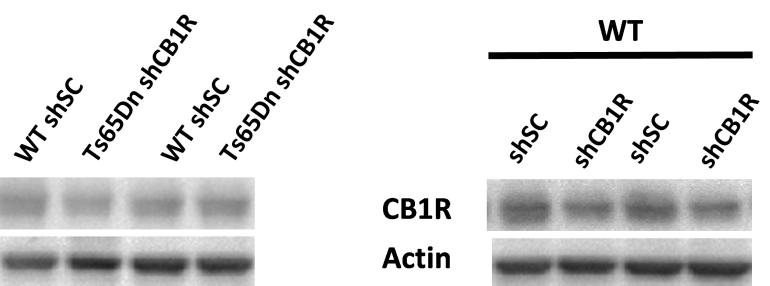

CB1R

Actin

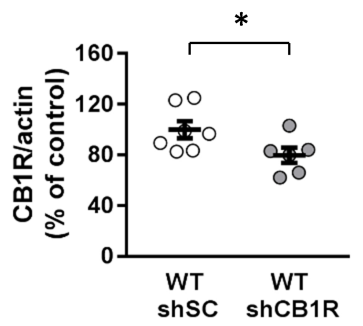


A<smiles>CCCC1CCCC1CCC</smiles>

Rimonabant

$1 \mathrm{mg} / \mathrm{kg}$

\begin{tabular}{l|l|l|l|l|l|l|l|}
\hline 1 & 2 & 3 & 4 & 5 & 6 & 7 & 8 \\
\hline
\end{tabular}

Behavioral tests/ LTP recordings/ Cellular proliferation
B NORT

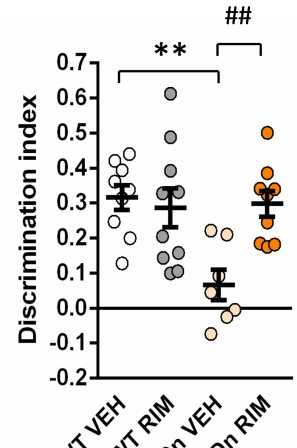

C NORT

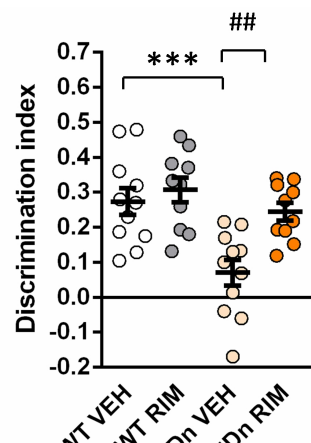

D

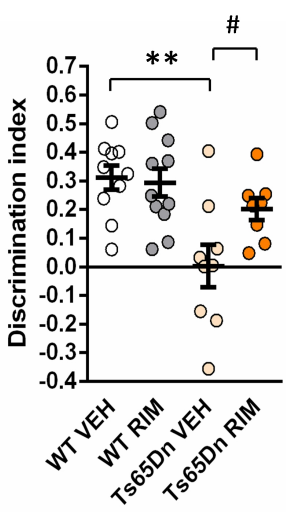

E

NORT

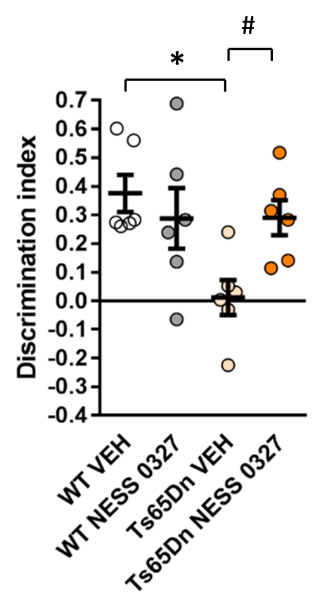


A

$$
\text { ○ WTVEH }
$$<smiles>[Tl]</smiles>

- Ts65Dn VEH

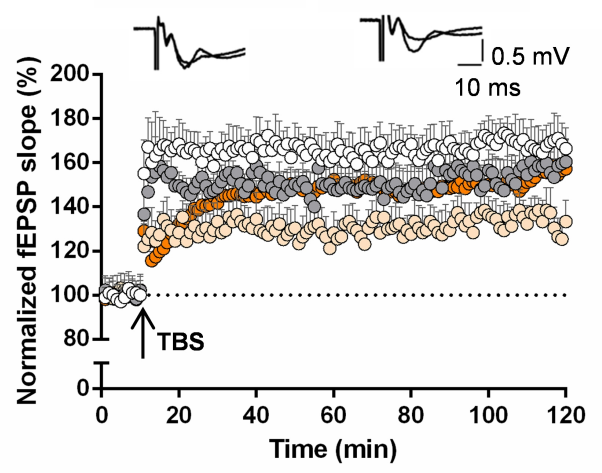

C

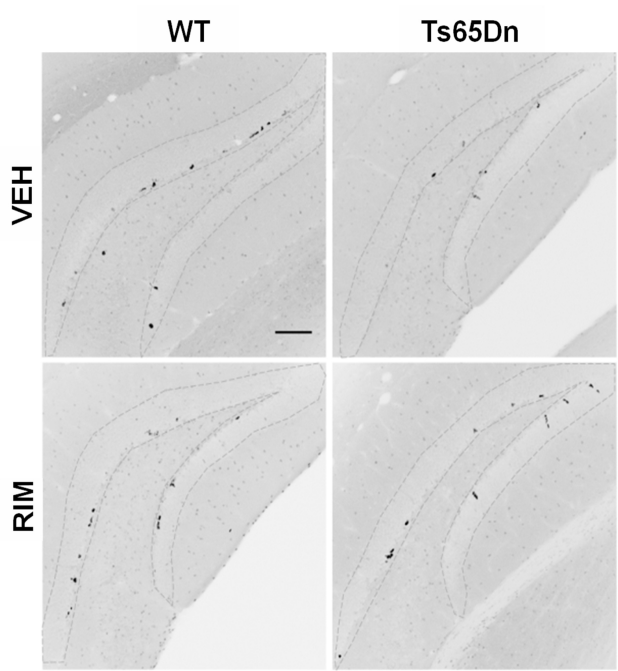

B

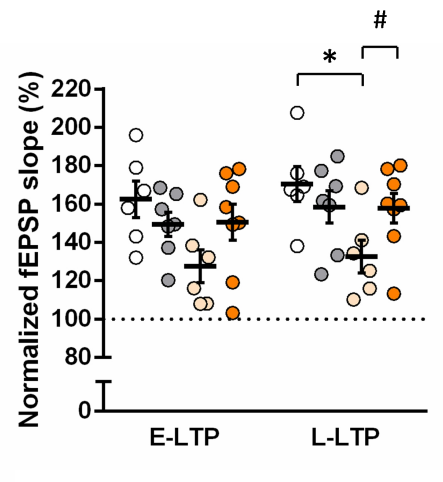

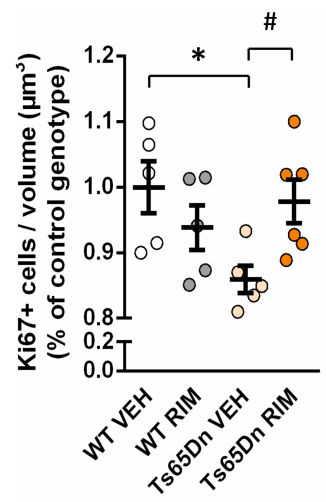


A

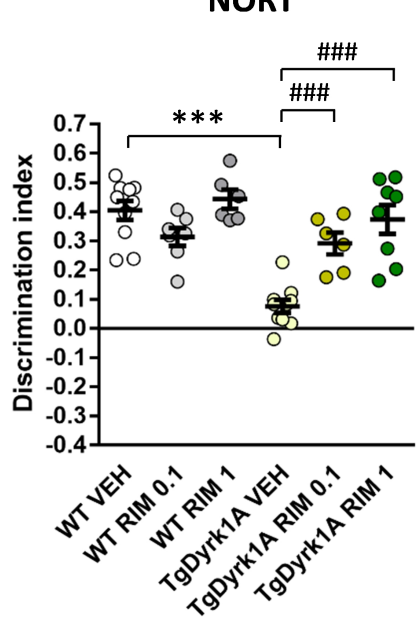

B

NPRT

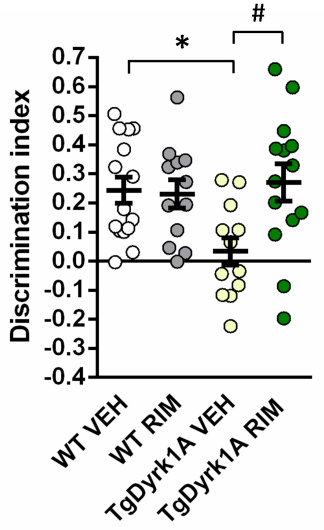

C

NORT

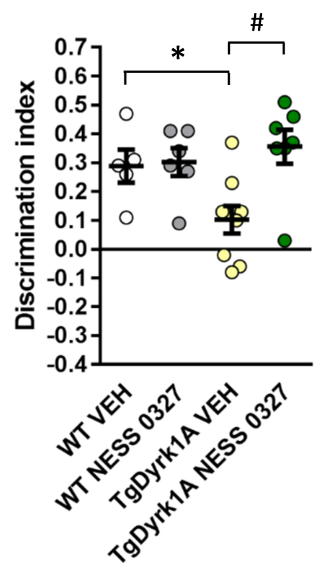


A

- WT VEH

证

- TgDyrk1A VEH

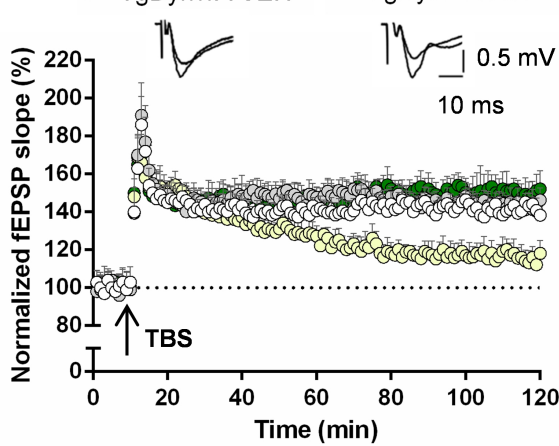

C

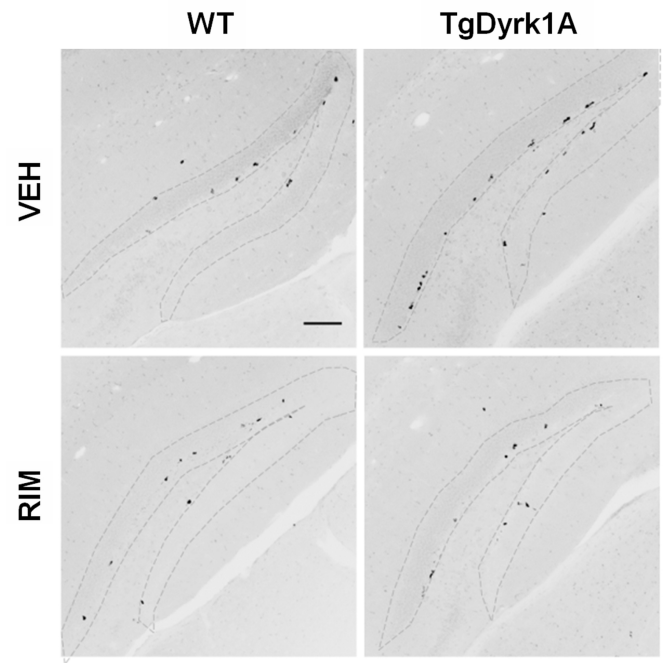

D

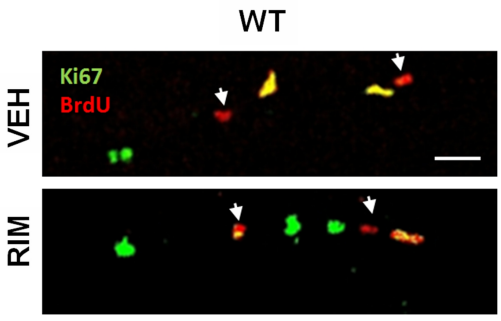

TgDyrk1A

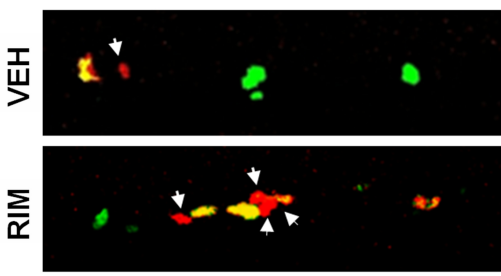

B
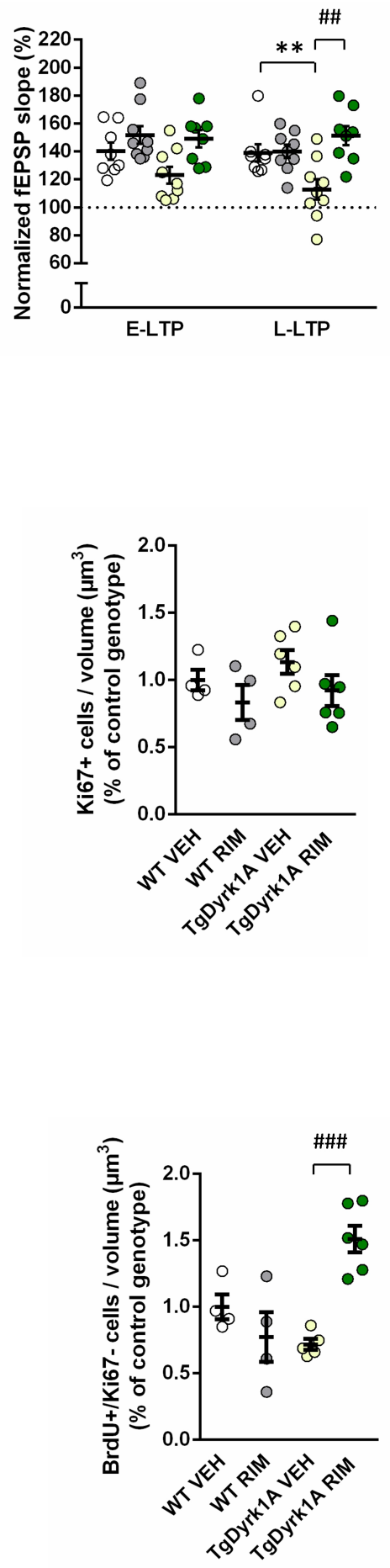


\begin{tabular}{lcccl}
\hline & \multicolumn{2}{c}{ Hippocampus } & \multicolumn{2}{c}{ Whole brain } \\
\hline & WT & Ts65Dn & WT & Ts65Dn \\
\cline { 2 - 5 } AEA & $100 \pm 4.3$ & $82.3 \pm 4.5 * *$ & $100 \pm 4.3$ & $86.9 \pm 8.5$ \\
DEA & $100 \pm 3.3$ & $87.9 \pm 3.3 *$ & $100 \pm 3.6$ & $97.5 \pm 6.3$ \\
DHEA & $100 \pm 3.4$ & $90.0 \pm 3.4 *$ & $100 \pm 4.0$ & $84.0 \pm 3.4 * *$ \\
2-AG & $100 \pm 5.6$ & $107.5 \pm 6.3$ & $100 \pm 2.9$ & $105.0 \pm 6.0$ \\
2-LG & $100 \pm 3.5$ & $99.2 \pm 5.7$ & $100 \pm 4.9$ & $94.7 \pm 12.3$ \\
2-OG & $100 \pm 2.5$ & $95.4 \pm 5.6$ & $100 \pm 9.0$ & $94.2 \pm 9.7$
\end{tabular}

Table 1. Relative levels of endocannabinoids and related compounds in hippocampal and whole brain homogenates of Ts65Dn and WT controls. Data is expressed as mean \pm s.e.m (hippocampus: WT, $\mathrm{n}=18$; Ts65Dn, $\mathrm{n}=15$; whole brain: WT, $\mathrm{n}=9$; Ts65Dn, $\mathrm{n}=8$ ). ${ }^{*} \mathrm{p}<0.05, * * \mathrm{p}<0.01$ (genotype effect) by Student's t-test. 


\section{Supplementary material}

A

Hippocampus

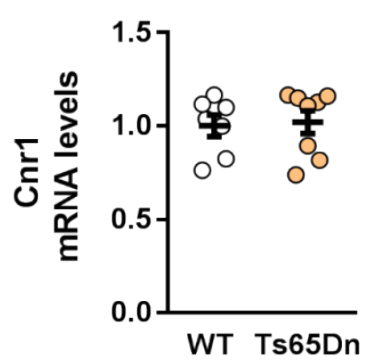

C

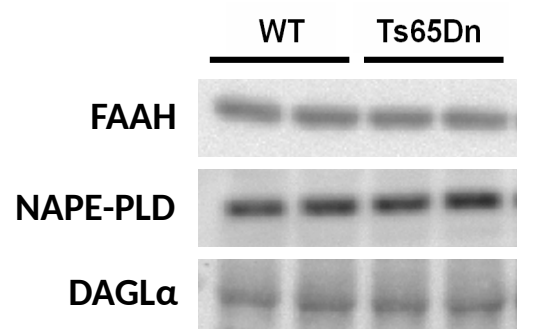

Actin

MAGL

Actin
B
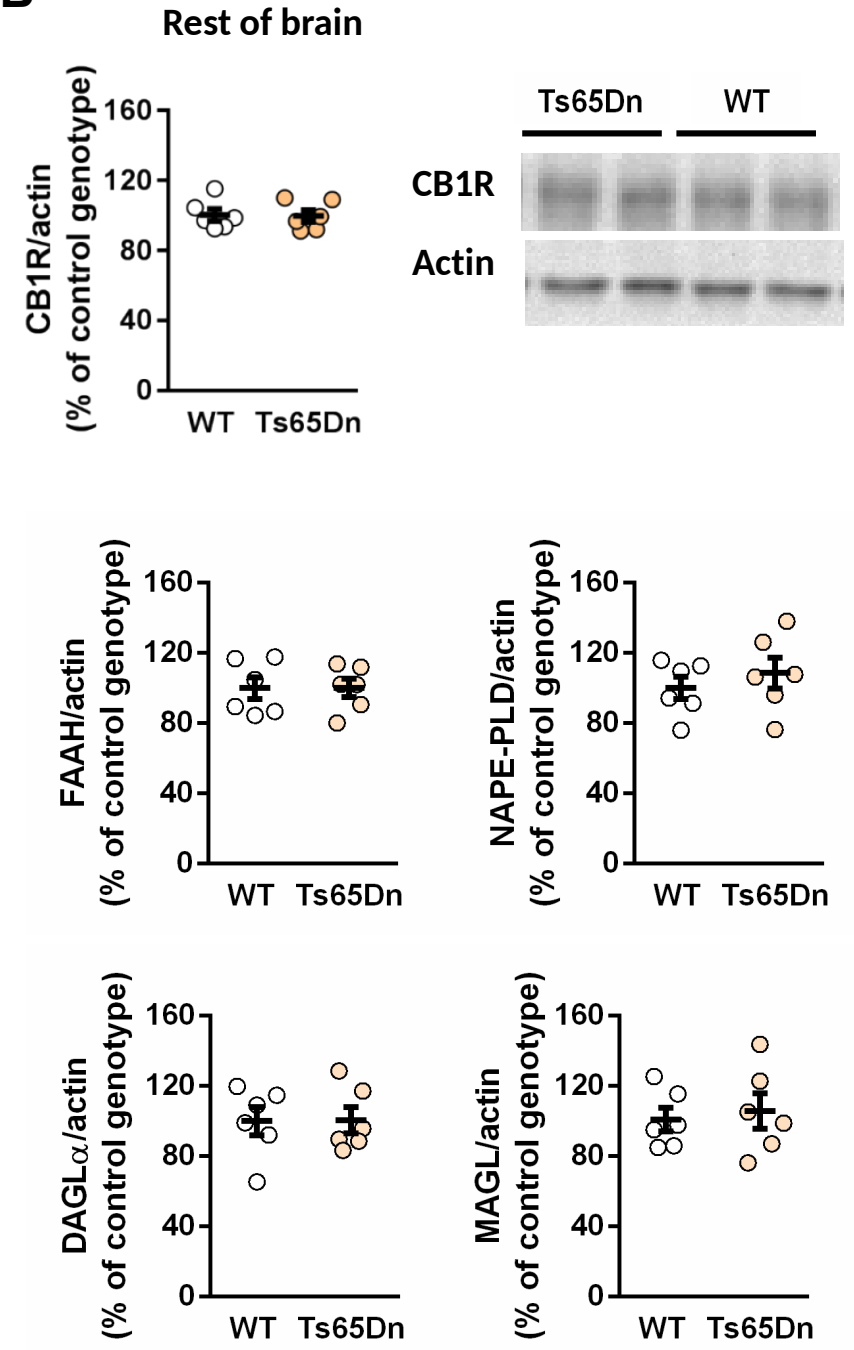

Figure $S$ 1. Expression of $C B 1 R$ and the main endocannabinoid-metabolizing enzymes in Ts65Dn mice. (A) Analysis of Cnrl mRNA expression in hippocampus of WT and Ts65Dn mice. (B) Quantification and representative images of CB1R protein expression levels of whole brain samples where hippocampus was removed. (C) Quantification and representative images of hippocampal expression levels of the main enzymes involved in the synthesis and inactivation of endocannabinoids including fatty acid amide hydrolase (FAAH), N-acyl-phosphatidylethanolamine-hydrolyzing phospholipase D (NAPE-PLD), diacylglycerol- $\alpha$ lipase (DAGL $\alpha$ ) and monoacylglycerol lipase (MAGL). Actin was used as the housekeeping control (WT, $\mathrm{n}=6$; Ts65Dn, $\mathrm{n}=6$ ). Distribution of individual data with mean \pm s.e.m. Statistical significance was calculated by Student's t-test. 
A

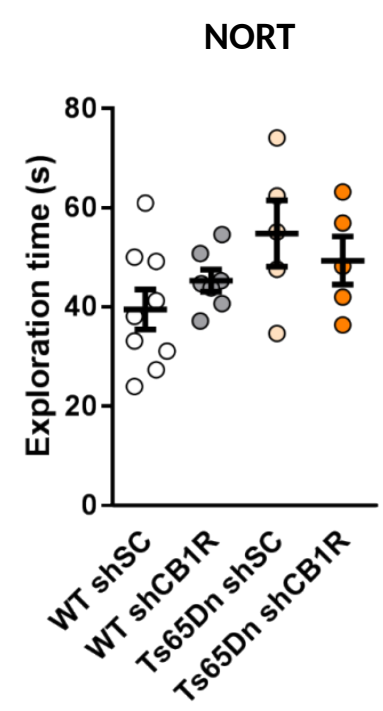

D

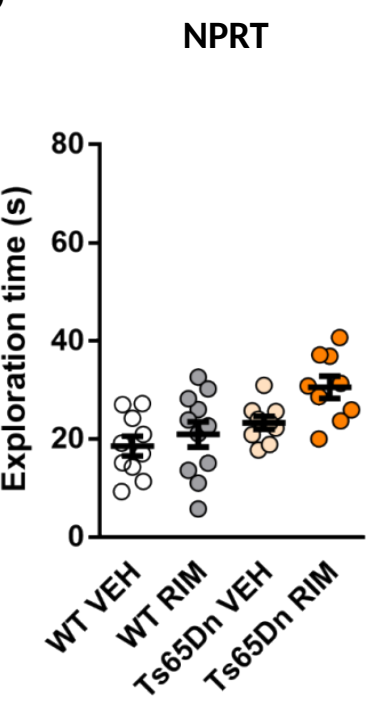

B

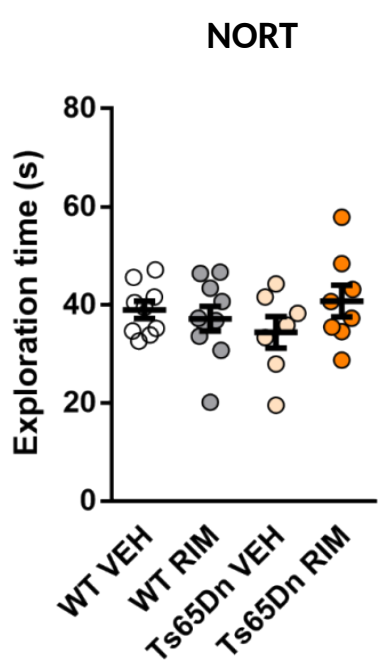

E
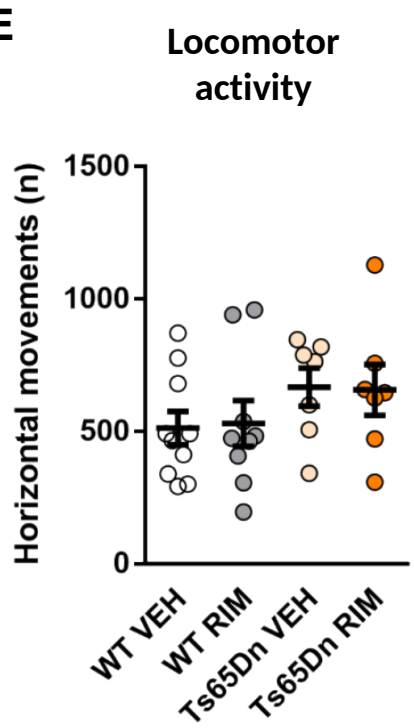

C

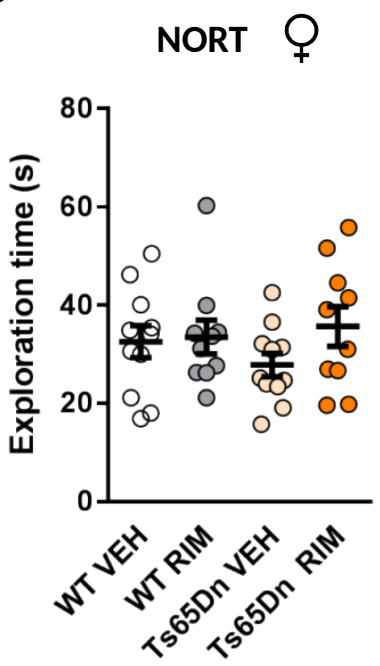

$\mathbf{F}$

NORT

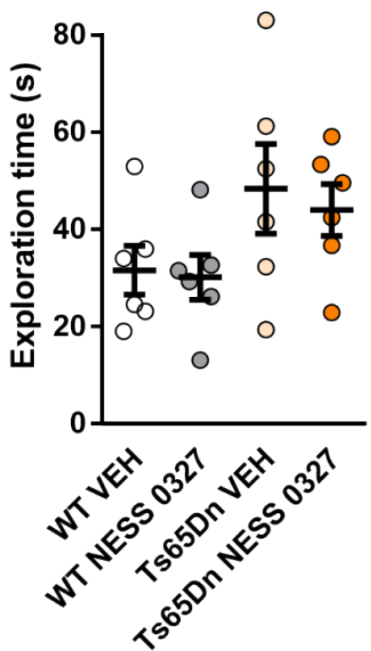

Figure S 2. Total object exploration times mice in hippocampal-dependent memory tasks and locomotor activity after pharmacological targeting of CB1R. (A) Total object exploration times during test phase of novel object-recognition test (NORT) of mice injected with shSC- and shCB1R-containing adenoassociated viral vectors. (B-C) Total object exploration times during test phase of NORT of male (B) and female (C) mice treated with vehicle (VEH) or rimonabant (RIM). (D) Total object exploration times during test phase of novel place-recognition test (NPRT) of mice treated with vehicle or rimonabant. (E) Photocell counts of locomotor activity during a $30 \mathrm{~min}$ period of WT and Ts65Dn mice treated with vehicle or rimonabant (WT VEH, $\mathrm{n}=10$; WT RIM, n=9; Ts65Dn VEH, n=7; Ts65Dn RIM, n=7). (F) Total object exploration times during test phase of NORT of mice treated with vehicle or NESS 0327. Distribution of individual data with mean \pm s.e.m. Statistical significance was calculated by two-way ANOVA. 
A

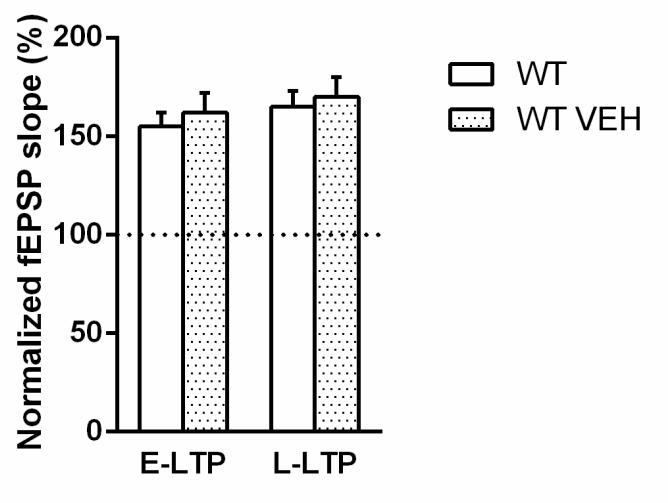

C

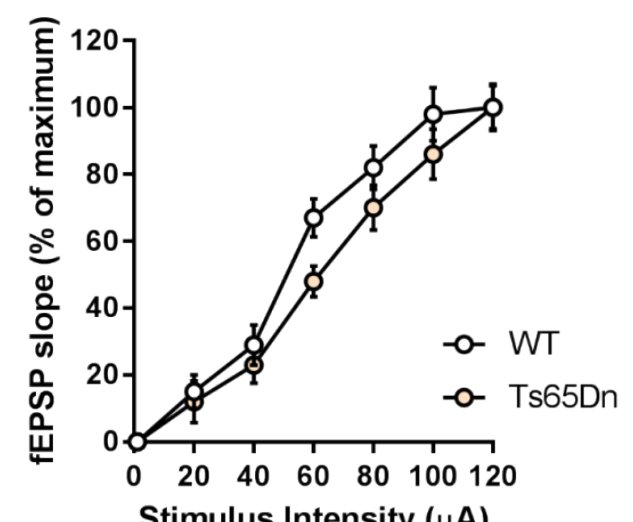

E
B

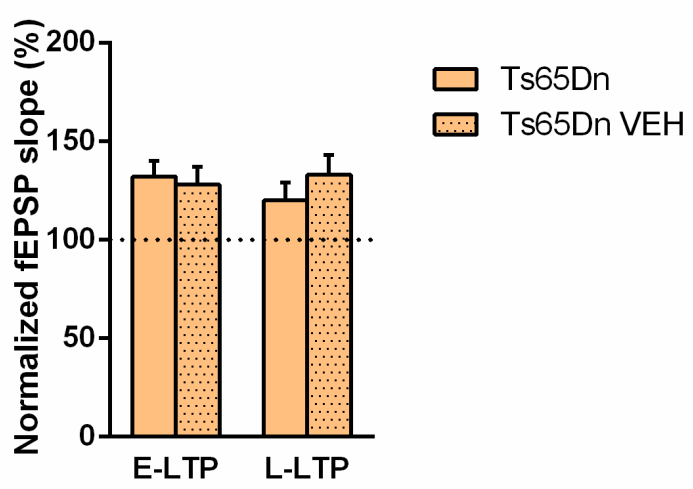

D

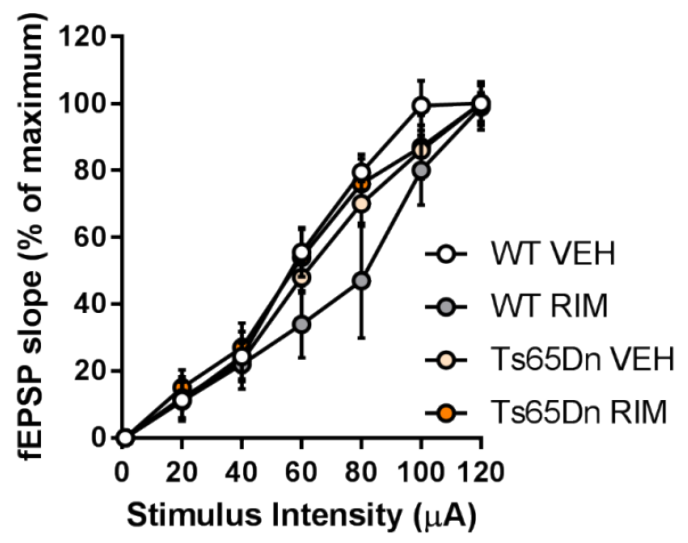

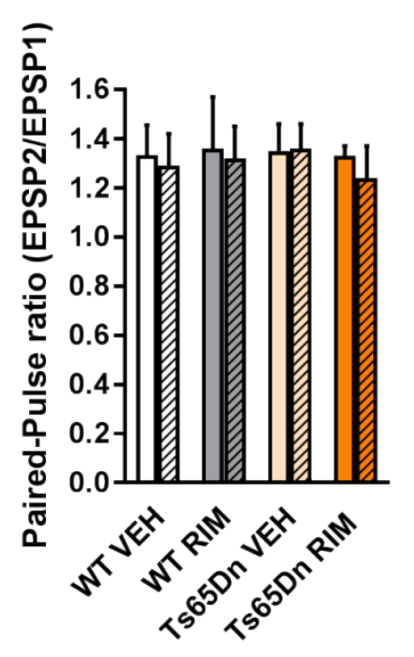

Figure S 3. Effect of vehicle treatment over LTP and basal transmission and paired-pulse facilitation on WT and Ts65Dn mice. (A-B) Average LTP of the last 5 min of recordings in E-LTP and L-LTP (60 and 120 min post-tetanus period, respectively) in hippocampal slices from naïve mice and mice treated with vehicle (VEH), WT (A) and Ts65Dn (B) (n=6-8). (C) Stimulation input/output curves of naïve WT and Ts65Dn mice. (D) Stimulation input/output curves of WT and Ts65Dn mice treated with VEH and rimonabant (RIM). (E) Paired-pulse facilitation before (baseline) and after L-LTP in WT and Ts65Dn mice treated with VEH or RIM. Data are shown as the mean \pm s.e.m. 
A
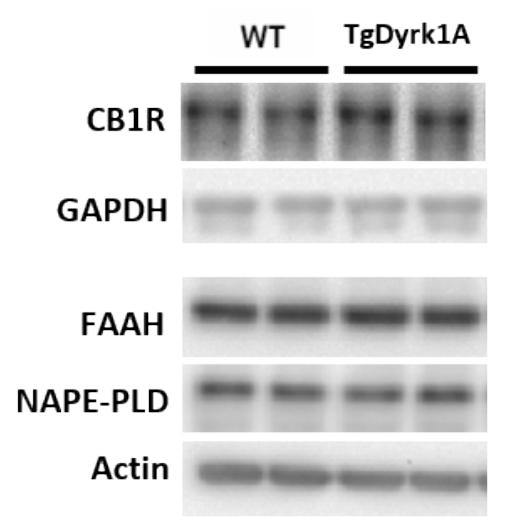

DAGL $\alpha$

MAGL

Actin
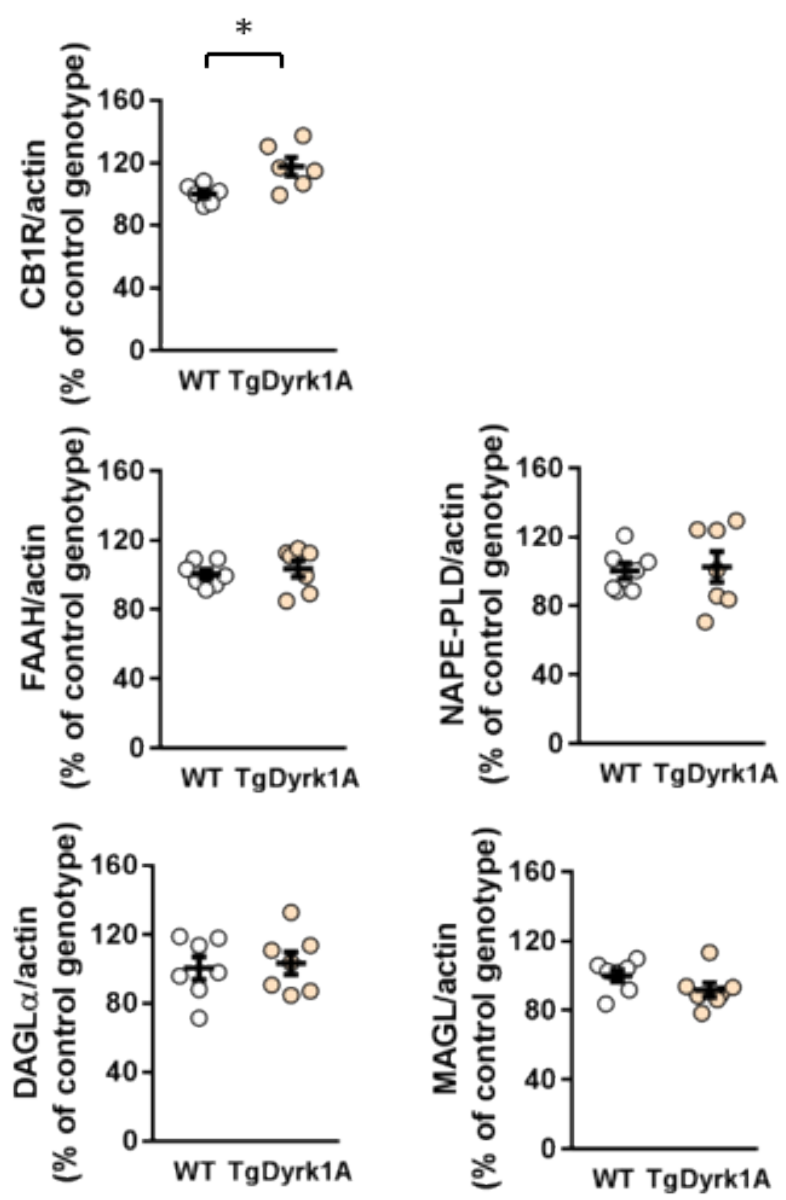

Figure S 4. Hippocampal expression of CB1R and the main endocannabinoidmetabolizing enzymes in the TgDyrk1A mouse. (A) Quantification and representative images of hippocampal protein levels of CB1R and the main endocannabinoidmetabolizing enzymes including fatty acid amide hydrolase (FAAH), N-acylphosphatidylethanolamine-hydrolyzing phospholipase D (NAPE-PLD), diacylglycerol$\alpha$ lipase (DAGL $\alpha$ ) and monoacylglycerol lipase (MAGL). Actin or GAPDH was used as the housekeeping control (WT, n=6-7; TgDyrk1A, n=6-7). Distribution of individual data with mean \pm s.e.m. ${ }^{*} \mathrm{p}<0.05$ by Student's t-test. 
A

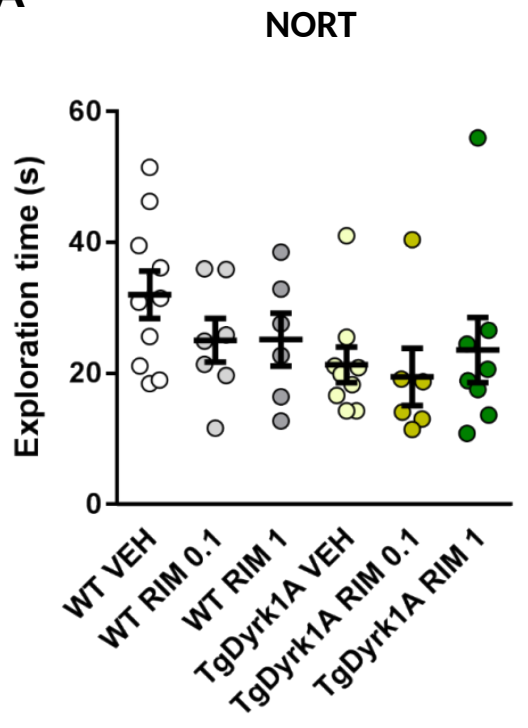

B

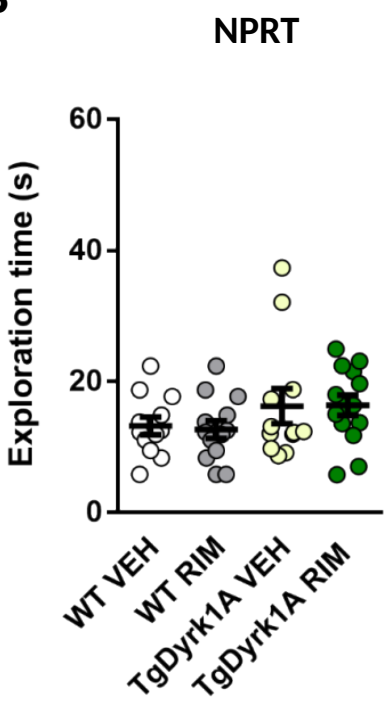

C

Figure $S$ 5. Total object exploration times of TgDyrk1A mice in hippocampaldependent tasks. (A-B) Total object exploration time during test phase of novel objectrecognition test (NORT) (A) and novel place-recognition test (NPRT) (B) of mice treated for 7 days with vehicle (VEH) or rimonabant (RIM) $(0.1 \mathrm{mg} / \mathrm{kg}$ and $1 \mathrm{mg} / \mathrm{kg})$. (C) Total exploration times of mice treated with vehicle or NESS $0327(0.1 \mathrm{mg} / \mathrm{kg})$. Distribution of individual data with mean \pm s.e.m. Statistical significance was calculated by two-way ANOVA. 
A
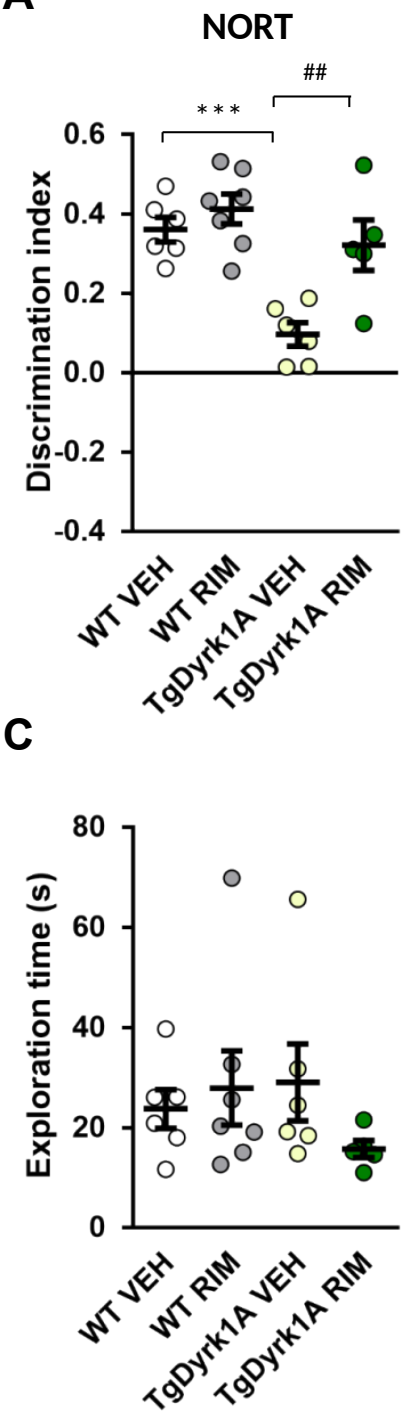

B NORT
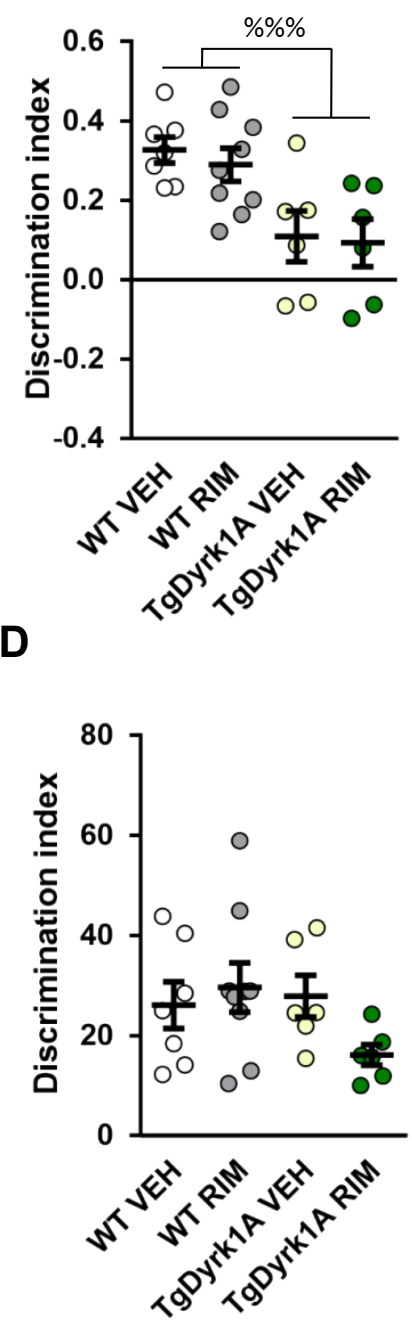

Figure $S$ 6. Effect of rimonabant withdrawal in TgDyrk1A mice in the novel object-recognition test. (A-B) Discrimination index after 2 weeks (A) and 4 weeks (B) of vehicle (VEH) or rimonabant (RIM) $(1 \mathrm{mg} / \mathrm{kg})$ treatment withdrawal in novel objectrecognition (NORT) ( 2 weeks; WT VEH, $\mathrm{n}=6$; WT RIM, $\mathrm{n}=7$; TgDyrk1A VEH, $\mathrm{n}=6$; TgDyrk1A RIM, n=5; 4 weeks; WT VEH, n=7; WT RIM, n=9; TgDyrk1A VEH, n=6; TgDyrk1A RIM, n=6). (C-D) Total object exploration times during test phase of NORT after 2 weeks (C) and 4 weeks (D) of treatment withdrawal. Distribution of individual data with mean \pm s.e.m. $* * * p<0.001$ (genotype effect); \#\# $\mathrm{p}<0.001$ (treatment effect) by Newman-Keuls post hoc test following two-way ANOVA and by main effect of the genotype $(\% \% \% \mathrm{p}<0.0001)$ with non-significant interaction (B). 
A

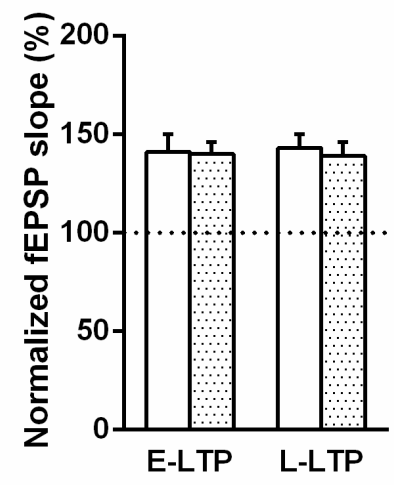

C

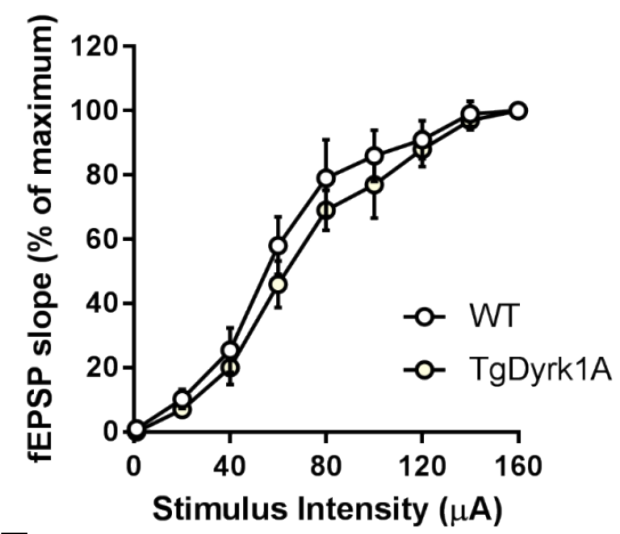

E

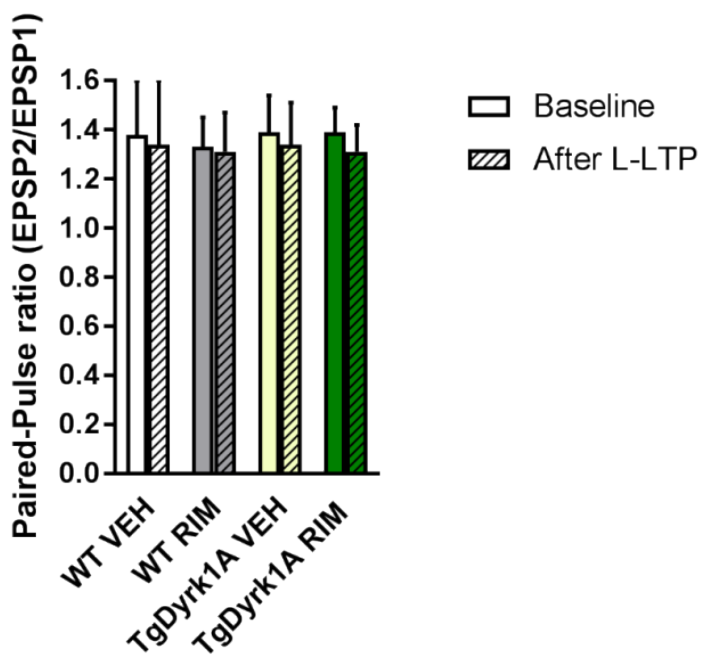

B

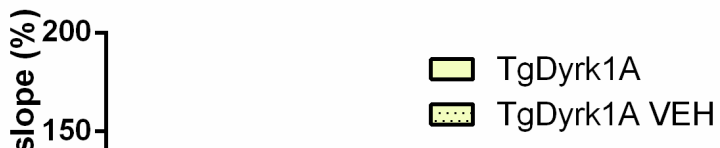

D

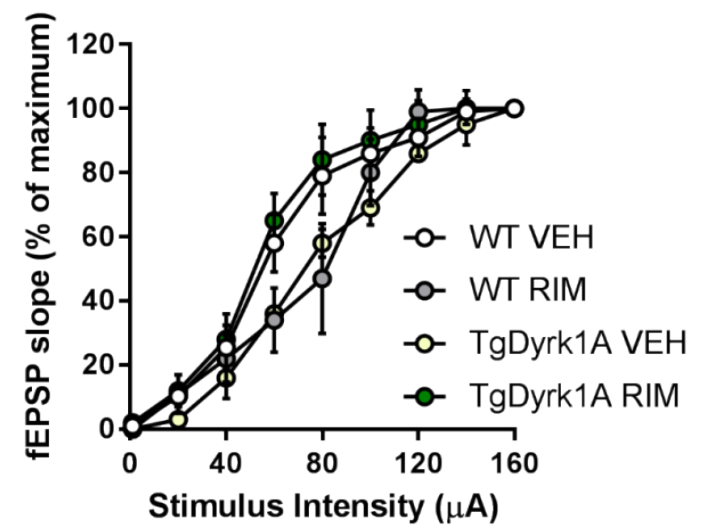

Figure S 7. Effect of vehicle treatment over LTP and basal transmission and paired-pulse facilitation of WT and TgDyrk1A mice. (A-B) Average LTP of the last 5 min of recordings in E-LTP and L-LTP (60 and 120 min post-tetanus period respectively) in hippocampal slices from naïve mice and mice treated with vehicle (VEH), WT (A) and TgDyrk1A (B) (n=8-12). (C) Stimulation input/output curves of naïve WT and TgDyrk1A mice. (D) Stimulation input/output curves of WT and TgDyrk1A mice treated with VEH and rimonabant (RIM). (E) Paired-pulse facilitation before (baseline) and after L-LTP in WT and TgDyrk1A mice treated with VEH or RIM. Data are shown as the mean \pm s.e.m 